
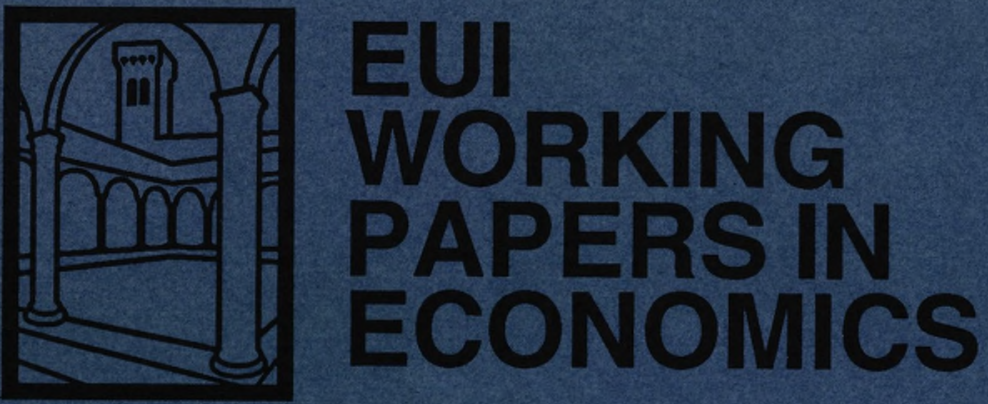

EUI Working Paper ECO No. 94/5

Dncompassing in Stationary Linear Dynamic Models

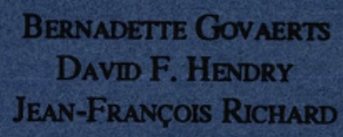

JP 
European University Library

|||||||||||||||||||||||||||||||||||||||||||||||||||||||||||||||||||||||||||

$300010015 \quad 49742$

\section{Please note}

As from January 1990 the EUI Working Paper Series is divided into six sub-series, each sub-series is numbered individually (e.g. EUI Working Paper ECO No. 90/1). 
EUROPEAN UNIVERSITY INSTITUTE, FLORENCE ECONOMICS DEPARTMENT

EUI Working Paper ECO No. 94/5

Encompassing in Stationary Linear Dynamic Models BERNADETTE GOVAERTS

DAVID F. HENDRY

JEAN-FRANÇOIS RICHARD

BADIA FIESOLANA, SAN DOMENICO (FI) 
All rights reserved.

No part of this paper may be reproduced in any form without permission of the authors.

(C) Bernadette Govaerts, David F. Hendry, Jean-François Richard

Printed in Italy in February 1994

European University Institute

Badia Fiesolana

I - 50016 San Domenico (FI)

Italy 


\title{
Encompassing in Stationary Linear Dynamic Models
}

\author{
Bernadette Govaerts, \\ Solvay \& Cie, Bruxelles, Belgium, \\ David F. Hendry \\ Nuffield College, Oxford, UK, \\ and \\ Jean-François Richard \\ University of Pittsburg, Pennsylvania, USA.
}

October 1993

\begin{abstract}
A model M1 encompasses a rival model M2 if M1 can explain M2's results. A Wald Encompassing Test (WET) checks if a statistic of interest to M2 coincides with an estimator of its predicted value under Mt. We propose techniques for evaluating WETs in stationary, linear, dynamic, single equations with weakly exogenous regressors, extending results for strong exogeneity. Dynamics can constrain M1's predictions of M2's findings, so encompassing tests can differ from existing tests as examples illustrate. Their asymptotic power functions are compared with the outcomes in a small Monte Carlo. The results support the use of parsimonious encompassing tests.
\end{abstract}

Keywords: Encompassing; dynamics; weak exogeneity; parsimony; Monte Carlo.

This research was financed in part by grants B00220012 and R000231184 from the U.K. Economic and Social Research Council. Helpful comments from Jean-Pierre Florens, Grayham Mizon, Mark Steel and two anonymous referees are gratefully acknowledged. This paper was presented to an Econometrics Workshop at the EUI in September 1993.

Proofs and reprints should be sent to the second author at Nuffield College, Oxford, OX1 1NF UK. 


\section{Introduction}

One model $M_{1}$ is said to encompass a rival model $M_{2}$ of the same variable $y$ if the former can account for the results obtained by the latter. This notion is a natural component of a progressive research strategy and has been formalized in the econometric literature: see Hendry and Richard [1990] for an overview and bibliographic perspective.

We will first define encompassing at the level of estimated models, emphasizing dynamic equations, relate it to a more heuristic concept and to nesting, discuss testing for encompassing, then extend the definitions to conditional settings. Our discussion draws on Florens, Hendry and Richard [1991] to which the reader is referred for a formal analysis.

Let $M_{1}$ and $M_{2}$ denote two competing parametric dynamic models with no exogenous variables. Their (sequential) density functions for a common vector $\boldsymbol{y}_{\mathrm{t}}$ are $f\left(\boldsymbol{y}_{\mathrm{t}} \mid \boldsymbol{Y}_{\mathrm{t}-1}, \boldsymbol{\alpha}\right)$ for $\alpha \in \mathcal{A}$ and $g\left(\boldsymbol{y}_{\mathrm{t}} \mid \boldsymbol{Y}_{\mathrm{t}-1}, \boldsymbol{\delta}\right)$ for $\delta \in \mathcal{D}$. The matrix $\boldsymbol{Y}_{\mathrm{t}-1}=\left(\mathbf{y}_{\mathrm{t}-1}, \ldots, \boldsymbol{y}_{1}\right)$, thereby groupin observations prior to period $t$. Observations start at $t=1$, and initial conditions are assumeil to be known. ${ }^{1}$ The models are called estimated in that they are provided with estimators $\hat{\boldsymbol{\alpha}}_{\mathrm{T}}$ and $\hat{\boldsymbol{\delta}}_{\mathrm{T}}$ for any finite sample $\boldsymbol{Y}_{\mathrm{T}}$. Let $\hat{\mathrm{M}}_{1}=\left(\mathrm{M}_{1}, \hat{\boldsymbol{\alpha}}_{\mathrm{T}}\right)$ and $\hat{\mathrm{M}}_{2}=\left(\mathbf{M}_{2}, \hat{\boldsymbol{\delta}}_{\mathrm{T}}\right)$.

Definition 1: $\hat{\mathrm{M}}_{1}$ exactly encompasses $\hat{\mathrm{M}}_{2}$ if and only if there exists a sequence of function; $\left\{\boldsymbol{\lambda}_{\mathrm{T}}\right\}$ such that $\hat{\boldsymbol{\delta}}_{\mathrm{T}}=\boldsymbol{\lambda}_{\mathrm{T}}\left(\hat{\boldsymbol{\alpha}}_{\mathrm{T}}\right), \mathrm{M}_{1}$-almost surely.

When attention is restricted to a subset $\boldsymbol{\delta}_{1}$ of $\boldsymbol{\delta}$, definition 1 applies subject to the qualification 'with respect to $\hat{\delta}_{1 \mathrm{~T}}$ '.

In general, we would not expect encompassing to hold exactly for finite sample sizes, even if $M_{1}$ were the data generation process (DGP). A weaker requirement is that of asymptotic encompassing, which we refer to as encompassing when no ambiguity arises:

Definition 2: $\hat{\mathrm{M}}_{1}$ asymptotically encompasses $\hat{\mathrm{M}}_{2}$ (denoted by $\hat{\mathrm{M}}_{1} \mathcal{E} \hat{\mathrm{M}}_{2}$ ) if and only if there exists a function $\boldsymbol{\lambda}$ such that $\hat{\boldsymbol{\delta}}_{\mathrm{T}}=\boldsymbol{\lambda}\left(\hat{\boldsymbol{\alpha}}_{\mathrm{T}}\right)+\mathrm{O}_{\mathrm{p}}\left(T^{-\frac{1}{2}}\right), \mathrm{M}_{1}$-almost surely. ${ }^{2}$

The concept of asymptotic encompassing captures the heuristic notion that the DGP ought 10 encompass all competing models. If $\mathrm{M}_{1}$ were the DGP, asymptotic encompassing would

\footnotetext{
1 This assumption is largely for notational convenience: the specification of $M_{1}$ and $M_{2}$ can be extended so incorporate sampling distributions for $\boldsymbol{Y}_{0}$.

2 The order of convergence can be adapted to the class of models under consideration. $1 / \sqrt{ } \Gamma$ is appropriate for the present paper where we consider stationary processes.
} 
generally hold under appropriate technical conditions, with $\lambda(\boldsymbol{\alpha})$ being given by the plim of $\hat{\boldsymbol{\delta}}_{\mathrm{T}}$ under $\mathrm{M}_{1}$. In particular, if $\hat{\boldsymbol{\delta}}_{\mathrm{T}}$ were a pseudo-maximum likelihood (ML) estimator, $\lambda(\alpha)$ would coincide with the pseudo-true value associated with the Kullback-Leibler information criterion (KLIC): see e.g. Sawa [1977], Kent [1986] or Gourieroux and Montfort [1991].

If we define nesting such that it implies the existence of a function $\delta=d(\alpha)$, and use an estimation procedure which is equivariant over such a function, then nesting implies encompassing. However, nesting is often defined by the weaker requirement that the KLIC of $M_{2}$ relative to $M_{1}$ be zero (see e.g. Pesaran [1987] or Gourieroux and Montfort, 1991). Then nesting also implies asymptotic encompassing for estimators that are asymptotically equivalent to (pseudo-) ML. Naturally, encompassing does not imply nesting as illustrated by the DGP encompassing all rival models, whether formally nested or not within it. The distinction between the two concepts of nesting is irrelevant to the analysis below and si, $M_{1} \subset M_{2}$ reads as ' $M_{1}$ is nested in $M_{2}$ ' without qualification.

From the perspective of econometric modelling, an important concept is parsimonious encompassing which determines whether a 'simple' model is capable of capturing the salient features of a more 'general' model within which it is nested.

Definition 3: $\hat{\mathrm{M}}_{1}$ parsimoniously encompasses $\hat{\mathrm{M}}_{2}\left(\hat{\mathrm{M}}_{1} \mathcal{E}_{\mathrm{p}} \hat{\mathrm{M}}_{2}\right)$ if and only if (i) $\mathrm{M}_{1} \subset \mathrm{M}_{2}$ and (ii) $\hat{\mathrm{M}}_{1} \mathcal{E} \hat{\mathrm{M}}_{2}$.

The concept of parametric encompassing in Mizon and Richard [1986] is closely related to definitions 1 and 2 (asymptotically), but restricts $\lambda_{\mathrm{T}}$ to be a pseudo-true value. That restriction creates conceptual problems (such as loss of transitivity) but delivers an operational concept that has important unifying features for testing nested and non-nester hypotheses.

Tests of whether or not $\hat{M}_{1}$ encompasses $\hat{M}_{2}$ are generically based on measures of divergence between $\hat{\boldsymbol{\delta}}_{\mathrm{T}}$ and $\boldsymbol{\lambda}_{\mathrm{T}}\left(\hat{\boldsymbol{\alpha}}_{\mathrm{T}}\right)$ for some suitable choice of $\left\{\boldsymbol{\lambda}_{\mathrm{T}}\right\}$ (see Florens et al, 1991). Typically one aims at selecting a sequence $\left\{\boldsymbol{\lambda}_{\mathrm{T}}\right\}$ which minimizes the divergence of $\hat{\mathrm{M}}_{2}$ relative to $\hat{\mathrm{M}}_{1}$, but this often results in intractable functional optimization problem:, st that approximate solutions must be considered. Given the previous discussion, possible candidates are (finite sample or asymptotic) pseudo-true values. Wald encompassing test 
(WET) statistics, introduced by Mizon and Richard [1986] and central to the objectives of the present paper, rely upon pseudo-true values to examine whether or not the encon!passing difference $\sqrt{ } \mathrm{r}\left[\hat{\boldsymbol{\delta}}_{\mathrm{T}}-\boldsymbol{\lambda}\left(\hat{\boldsymbol{\alpha}}_{\mathrm{T}}\right)\right]$ is significant on $\mathrm{M}_{1}$ (see section 2 below).

Consider the case where the competing models include a vector of weakly exogenotis variables. As discussed in Engle, Hendry and Richard [1983], weak exogeneity implies that there can be no efficiency gain in designing estimators which depend on the specification of the exogenous variables' process. Hence no such estimators will be considered in the present paper. Nevertheless, the sampling distribution of $\hat{\boldsymbol{\delta}}_{\mathrm{T}}$ on $\mathrm{M}_{1}$ is bound to depend on the characteristics of the exogenous process since, in particular, $M_{2}$ is mis-specified from the viewpoint of $M_{1}$. Hence generalizations of definitions 1-3 for conditional models require explicit consideration of the exogenous process and an issue of robustness arises.

Let $\mathrm{M}_{\mathrm{c}}$ denote a sequential model for the exogenous variables $\boldsymbol{r}_{\mathrm{t}}$, with density function $\boldsymbol{h}\left(\boldsymbol{r}_{\mathrm{t}} \mid \boldsymbol{S}_{\mathrm{t}-1}, \tau\right)$ where $S_{\mathrm{t}-1}$ regroups past observations on $\boldsymbol{s}_{\mathrm{t}}^{\prime}=\left(y_{\mathrm{t}} \boldsymbol{r}_{\mathrm{t}}^{\prime}\right)$ and $\tau \in \Upsilon$ is a nuisanci: parameter. Let $\hat{\mathrm{M}}_{\mathrm{i}}^{\mathrm{c}}=\left(\hat{\mathrm{M}}_{\mathrm{i}}, \hat{\mathrm{M}}_{\mathrm{c}}\right)$ for $\mathrm{i}=1,2$.

Definition 4: $\hat{\mathrm{M}}_{1}$ encompasses $\hat{\mathrm{M}}_{2}$ given $\hat{\mathrm{M}}_{\mathrm{c}}$ if and only if $\hat{\mathrm{M}}_{1}^{c} \mathcal{E} \hat{\mathrm{M}}_{2}^{\mathrm{c}}$ relative to $\hat{\boldsymbol{\delta}}_{\mathrm{T}}$.

It is unreasonable in most applications to require that $M_{c}$ be more than just an auxiliary model, which could be severely mis-specified for the DGP, so we extend the definitions to it class of competing models $\boldsymbol{H}_{\mathrm{c}}$ (if only for consideration of robustness):

Definition 5: $\hat{M}_{1}$ encompasses $\hat{M}_{2}$ given $\hat{H}_{c}$, if and only if there exists $\hat{M}_{c}$ in $\hat{H}_{c}$ such that $\hat{\mathrm{M}}_{1}^{\mathrm{c}} \mathcal{E} \hat{\mathrm{M}}_{2}^{\mathrm{c}}$ relative to $\hat{\delta}_{\text {. }}$

The analysis of the choice of regressor problem in Mizon and Richard [1986] and Florens, Hendry and Richard [1988] can be reinterpreted within the context of thes: definitions. However, since they only considered cases where $y_{\mathrm{t}}$ does not Granger-cause $r_{\mathrm{t}}$ (see Granger, 1969), so that $r_{\mathrm{t}}$ is strongly exogenous in the sense of Engle et al. [1983], th: analysis simplifies considerably, and for practical purposes can be treated as a "fixed regressor' analysis. The question naturally arises as to whether their results remain valid once Granger causality feedbacks from $y_{\mathrm{t}}$ to $\boldsymbol{r}_{\mathrm{t}}$ are allowed.

To simplify notation for the rest of the analysis, we do not explicitly distinguish between models and their estimated counterparts, using $\mathrm{M}_{\mathrm{i}}$ as a shorthand for both. Following 
Hendry and Richard [1982], the limit of $\hat{M}_{i}$ under the DGP, equivalent to the reduction of $M_{i}$ from the DGP, is called an empirical model (see Hendry, 1993), and it is the characteristics of the empirical model which determine the outcome of any modelling exercise.

The two objectives of our paper can now be formulated. First, we propose general techniques for the evaluation of WET statistics for single equations estimated from stationary, linear, dynamic systems where the regressors contain lagged dependent and weakly exogenous variables. We derive conditions under which results obtained for strong exogeneity extend to weak exogeneity. Because of feedbacks from the endogenous to the conditioning variables, the rival models do not fully characterize the joint data density, which needs to be completed by an auxiliary system linking the non-modelled variables. The formulation of the completing model is important for the validity and power of the encompassing tests and section 3 proposes a general approach which ensures at least 1 consistent test procedure.

The other objective is to explore the fact that dynamics often constrain the predictions which one model can make of another's findings, and encompassing tests that exploit such information can differ from existing tests. Consider the rival dynamic models:

$\mathrm{M}_{1}: y_{\mathrm{t}}=\beta y_{\mathrm{t}-1}+\varepsilon_{1 \mathrm{t}}$

$\mathrm{M}_{2}: y_{\mathrm{t}}=\gamma y_{\mathrm{t}-2}+\varepsilon_{2 \mathrm{t}}$,

where $|\beta|<1$ (to ensure stationarity), and each model assumes its error to be independent normal, mean zero, with variance $\sigma_{\mathrm{i}}^{2}$, denoted $\mathrm{IN}\left(0, \sigma_{\mathrm{i}}^{2}\right)$. Then, $\mathrm{M}_{1}$ predicts $\gamma$ to be $\beta^{2}$, bat also predicts the presence of residual autocorrelation in $M_{2}$, since it views $M_{2}$ as:

$\mathrm{M}_{2}^{*}: y_{\mathrm{t}}=\beta^{2} y_{\mathrm{t}-2}+\varepsilon_{1 \mathrm{t}}+\beta \varepsilon_{1 \mathrm{t}-1}$.

These factors determine $M_{1}$ 's prediction of the estimate of $\gamma$ in $M_{2}$. The WET statistic is equivalent to the usual $F$-test for deleting $y_{\mathrm{t}-2}$ from the linear nesting model:

$\mathrm{M}_{\mathrm{n}}: y_{\mathrm{t}}=b y_{\mathrm{t}-1}+c y_{\mathrm{t}-2}+v_{\mathrm{t}}$.

Both tests are approximations in finite samples due to the dynamics.

If we switch the roles of the competing models, then $M_{2}$ predicts $\beta$ to be zero, aiu predicts the presence of an autoregressive error in $\mathrm{M}_{1}$. The $F$-test has the same form, but now tests if $b=0$, whereas the form of the WET statistic is noticeably different from the 
previous case due to the regressor in $M_{2}$ being at a longer lag than that in $M_{1}$. Such considerations extend to more interesting dynamic models which include regressors that are weakly exogenous for the parameters of interest under $M_{1}$.

The structure of the paper is as follows. Section 2 reviews results on encompassing tests in previously studied models, and section 3 extends those findings to stationary, linear dynamic models. The examples in section 4 illustrate implementation issues, including test power considerations. Section 5 concludes, and comments on extensions to integrated processes. The paper draws on Govaerts [1987] where additional results, proofs and examples are found (a copy is available from the first author upon request).

2. ENCOMPASSING TEST STATISTICS

This section summarizes the definitions and results needed for our later analysis. Proos, and additional details can be found in the literature noted in the introduction. We focus on parametric encompassing tests in the sense of Mizon and Richard [1986].

\subsection{WET statistics}

Ignoring for the present any complications arising from the treatment of exogenous variables, let $\tilde{\alpha}$ denote a consistent estimator of $\boldsymbol{\alpha}$ under $M_{1}$ and $\tilde{\phi}$ a statistic of interest in the context of $M_{2}$. The pseudo-true value $\phi_{\alpha}$ of $\tilde{\phi}$ under $M_{1}$ is:

$$
\phi_{\alpha}=\operatorname{plim}_{\mathrm{M}_{1}} \tilde{\boldsymbol{\phi}} \text {. }
$$

Let $\tilde{\Delta}_{\phi}$ denote the encompassing difference relative to $\tilde{\phi}$, namely the difference between $\ddot{\phi}$ and an estimate of its pseudo-true value $\phi_{\alpha}$ :

$$
\tilde{\Delta}_{\phi}=\tilde{\boldsymbol{\phi}}-\boldsymbol{\phi}_{\tilde{\alpha}}
$$

The limiting distribution of $\sqrt{T} \tilde{\Delta}_{\phi}$ on $M_{1}$ is:

$\sqrt{T} \tilde{\Delta}_{\phi} \stackrel{\mathrm{d}}{\vec{M}_{1}} \mathrm{~N}\left(0, \mathrm{~V}_{\alpha}\left[\sqrt{T} \tilde{\Delta}_{\phi}\right]\right)$ where $\stackrel{\overrightarrow{\mathrm{M}}_{1}}{\overrightarrow{\mathrm{N}}_{1}}$ "means is asymptotically distributed on $\mathrm{M}_{1}$ as . Also, $\mathrm{V}_{\alpha}\left[\sqrt{T} \tilde{\Delta}_{\phi}\right]$ is the asymptotic variance matrix of $\sqrt{T} \tilde{\Delta}_{\phi}$.

Using the estimated variance $\mathrm{V}_{\tilde{\alpha}}\left[\sqrt{T} \tilde{\Delta}_{\phi}\right]$, a WET statistic with respect to $\tilde{\boldsymbol{\phi}}$ is given by:

$$
\eta_{W}(\tilde{\boldsymbol{\phi}})=T \tilde{\Delta}_{\phi}^{\prime} \mathrm{V}_{\tilde{\alpha}}^{+}\left[\sqrt{T} \tilde{\Delta}_{\phi}\right] \tilde{\Delta}_{\phi} \stackrel{\mathrm{d}}{\overrightarrow{\mathrm{M}}_{1}} \chi^{2}(\rho)
$$

where $\rho$ is the rank of $V_{\tilde{\alpha}}\left[\sqrt{T} \tilde{\Delta}_{\phi}\right]$ and the superscript ${ }^{+}$denotes the Moore-Penrose inverse. 


\subsection{The choice of regressors problem}

The choice of regressors problem usually takes the form:

$$
\begin{aligned}
& \mathrm{M}_{1}: \boldsymbol{y}=\boldsymbol{X} \boldsymbol{\beta}+\varepsilon_{1}, \quad \varepsilon_{1} \sim \mathrm{N}\left(0, \sigma^{2} \boldsymbol{I}_{T}\right), \quad \boldsymbol{\alpha}=\left(\boldsymbol{\beta}, \sigma^{2}\right), \\
& \mathrm{M}_{2}: \boldsymbol{y}=\boldsymbol{Z} \boldsymbol{\gamma}+\boldsymbol{\varepsilon}_{2}, \boldsymbol{\varepsilon}_{2} \sim \mathrm{N}\left(0, \tau^{2} \boldsymbol{I}_{T}\right), \quad \boldsymbol{\delta}=\left(\boldsymbol{\gamma}, \tau^{2}\right),
\end{aligned}
$$

where $\boldsymbol{X}$ and $\boldsymbol{Z}$ are full column rank matrices of dimensions $T \times k$ and $T \times l$ respectively. We assume for convenience that $X$ and $Z$ have no common regressors; the general case is easily treated at the cost of more cumbersome algebra. In the rest of the paper, the overscript denotes (pseudo-) ML estimators, which coincide with ordinary least squares (OLS), except that the sums of squares in variance estimators are divided by $T$.

Another possible rival model for $M_{1}$ is $M_{n}$, the linear nesting model of $M_{1}$ and $M_{2}$ :

$$
\mathrm{M}_{\mathrm{n}}: \boldsymbol{y}=\boldsymbol{X} \boldsymbol{b}+\mathrm{Z} c+\boldsymbol{e}, \boldsymbol{e} \sim \mathrm{N}\left(0, v^{2} \boldsymbol{I}_{T}\right), \boldsymbol{d}=\left(\boldsymbol{b}, c, v^{2}\right) .
$$

We consider four classes of wET statistics, reflecting which parameters in $M_{2}$ or $M_{n}$ are $0_{i}$ interest to the builder of $M_{1}$. WET statistics against $M_{2}$ (non-nested encompassing) will b: denoted by $\eta_{\bullet}$ and against $M_{n}$ (parsimonious encompassing) by $\eta_{\bullet}^{\mathrm{p}}$.

(a) Complete WET statistic (CWET)

$$
\begin{array}{ll}
\eta_{C}=\eta_{W}(\tilde{\boldsymbol{\delta}}) & \eta_{C}^{\mathrm{p}}=\eta_{W}(\tilde{\boldsymbol{d}}) ; \\
\eta_{S}=\eta_{W}(\tilde{\gamma}) & \eta_{S}^{\mathrm{p}}=\eta_{W}(\tilde{\boldsymbol{c}}) ; \\
& \eta_{H}^{\mathrm{p}}=\eta_{W}(\tilde{\boldsymbol{b}}) ;
\end{array}
$$

(b) Simplification WET statistic (SWET)

(c) Hausman WET statistic (HWET)

(d) Variance WET statistic (VWET)

$$
\eta_{V}=\eta_{W}\left(\tilde{\tau}^{2}\right)
$$

Their precise expressions are found e.g. in Florens et al. [1988]. The statistics $\eta_{H}$ and $\eta_{V^{\prime}}^{\mathrm{p}}$ have been dropped because the Hausman WET statistic is not applicable in $M_{2}$ (since $M_{1}$ and $\mathrm{M}_{2}$ have no common regressors), and $\eta_{V}^{\mathrm{p}}$ is not defined because the encompassing difference for the variance of the nesting model $M_{n}$ is $O\left(T^{-1}\right)$.

A further important test in this context is the conventional $F$-test of the null hypothesis $c=0$ in $\mathrm{M}_{\mathrm{n}}$. Two versions of it can be given: $F_{C}$, the conventional small sample $F$-statistic: and $\eta_{F}$, an asymptotically equivalent version:

$$
\eta_{F}=\tilde{\sigma}^{-2} y^{\prime} Q_{X} Z\left(Z^{\prime} Q_{X} Z\right)^{-1} Z^{\prime} Q_{X} y \stackrel{\mathrm{d}}{\overrightarrow{\mathrm{M}}_{1}} \chi^{2}(l),
$$

where $Q_{X}=I-\boldsymbol{X}\left(\boldsymbol{X}^{\prime} \boldsymbol{X}\right)^{-1} \boldsymbol{X}^{\prime}$, so that:

$$
F_{C}=\frac{T-k-l}{T l} \eta_{F}\left(1-T^{-1} \eta_{F}\right)^{-1} \text {. }
$$

The WET statistics defined above and the $F$-statistic $\eta_{F}$ are closely related as shown in 
proposition 2.1 below. In the rest of the paper, equations of the forms:
(a) $\eta_{\bullet}=\eta_{F}$;
(b) $\eta_{\bullet} \underset{\mathrm{M}_{1}}{\approx} \eta_{F} ;$ and
(c) $\eta_{\bullet} \stackrel{\sim}{\mathrm{M}_{1}} \eta_{F}$

respectively denote (a) finite sample equality; (b) large sample equality $\left(\eta_{\bullet}=\eta_{F}+\mathrm{O}_{\mathrm{p}}\left(T^{-1}\right)\right.$ on $\left.\mathrm{M}_{1}\right)$; and (c) weak asymptotic equivalence $\left(\eta_{\bullet}=\eta_{F}+\mathrm{O}_{\mathrm{p}}(1)\right.$ on $\left.\mathrm{M}_{1}\right)$, where $\mathrm{O}_{\mathrm{p}}\left(T^{-\lambda}\right)$ and $o_{p}\left(T^{-\lambda}\right)$ are defined as in Mann and Wald [1943] and White [1984]. Using this notation, the main results available in the literature are:

Proposition 2.1: Under the assumption that $X$ and $Z$ are strongly exogenous, we have:

$$
\begin{aligned}
& \tilde{\gamma}-\gamma_{\tilde{\alpha}}=\left(Z^{\prime} Z\right)^{-1} Z^{\prime} Q_{X} y ; \\
& \tilde{\tau}^{2}-\tau_{\tilde{\alpha}}^{2}=-\frac{1}{T}(y+X \tilde{\beta})^{\prime} Z\left(Z^{\prime} Z\right)^{-1} Z^{\prime} Q_{X} y ; \\
& \eta_{C} \underset{\mathrm{M}_{1}}{\simeq} \eta_{S}=\eta_{F}=\eta_{S}^{\mathrm{p}}=\eta_{C}^{\mathrm{p}} .
\end{aligned}
$$

See e.g. Florens et al. [1988] for proofs. In other words we find:

(i) The SwET statistic of $\mathrm{M}_{1}$ against $\mathrm{M}_{2}$ is equal to the $F$-statistic, and is asymptotically equivalent to the CWET statistic;

(ii) The SWET statistic of $M_{1}$ against $M_{n}$ is equal to both the $F$-statistic and the CWET statistic;

(iii) $\quad M_{1} \mathcal{E} M_{2}$ if and only if $M_{1} \mathcal{E}_{\mathrm{p}} M_{\mathrm{n}}$; and:

(iv) Simplification encompassing entails variance encompassing in static linear model;; or equivalently, the implicit null hypothesis of $\eta_{S}$ is included in the implicit null hypothesis of $\eta_{V}$ (see Florens et al. [1988] for similar results for $\eta_{H}$ and $\eta_{H}^{\mathrm{p}}$ ).

A major objective of the present paper is to investigate under what conditions proposition 2.1 remains valid for weak exogeneity. For reasons of space, we restrict attention to the modified $F$-statistic $\eta_{F}$, together with the four WET statistics $\eta_{S}, \eta_{S}^{\mathrm{p}}, \eta_{C}$ and $\eta_{C}^{\mathrm{p}}$

\section{STATIONARY LINEAR DYNAMIC MODELS}

\subsection{The models}

Let $y_{\mathrm{t}}$ denote the value of the dependent variable, $\boldsymbol{r}_{\mathrm{t}}$ the set of all current variables believed weakly exogenous for the parameters of interest by either investigator, and $\mu$ the maximum lag length. Define $\boldsymbol{s}_{\mathrm{t}}^{\prime}=\left(y_{\mathrm{t}}, \boldsymbol{r}_{\mathrm{t}}^{\prime}\right), \boldsymbol{s}_{(\mathrm{t}-1)}^{\prime}=\left(s_{\mathrm{t}-1}, \ldots s_{\mathrm{t}-\mathrm{p}}\right)$ and $f_{\mathrm{t}}^{\prime}=\left(s_{\mathrm{t}}^{\prime}, \boldsymbol{s}_{(\mathrm{t}-1)}^{\prime}\right)$. Initial 
conditions are assumed to be known. The rival models $M_{1}$ and $M_{2}$ and the nesting model $\mathrm{M}_{\mathrm{n}}$ are formulated as:

$$
\begin{aligned}
& \mathrm{M}_{1}: y_{\mathrm{t}} \mid \boldsymbol{r}_{\mathrm{t}}, \boldsymbol{s}_{(\mathrm{t}-1)}-\operatorname{IN}\left(\boldsymbol{\beta}^{\prime} \boldsymbol{x}_{\mathrm{t}}, \sigma^{2}\right) ; \\
& \mathrm{M}_{2}: y_{\mathrm{t}} \mid \boldsymbol{r}_{\mathrm{t}}, \boldsymbol{s}_{(\mathrm{t}-1)} \sim \operatorname{IN}\left(\gamma^{\prime} z_{\mathrm{t}}, \tau^{2}\right) ; \\
& \mathrm{M}_{\mathrm{n}}: y_{\mathrm{t}} \mid \boldsymbol{r}_{\mathrm{t}}, \boldsymbol{s}_{(\mathrm{t}-1)} \sim \operatorname{IN}\left(\boldsymbol{b}^{\prime} x_{\mathrm{t}}+c^{\prime} z_{\mathrm{t}}, v^{2}\right),
\end{aligned}
$$

where $x_{\mathrm{t}}$ and $z_{\mathrm{t}}$ are selections of $k$ and $l$ variables in $\left(\boldsymbol{r}_{\mathrm{t}}, \boldsymbol{s}_{(\mathrm{t}-1)}\right)$. To derive the WET statistics, an auxiliary process is needed for the non-modelled variables. The completing model is defined as:

$$
\mathrm{M}_{\mathrm{c}}: r_{\mathrm{t}} \mid s_{(\mathrm{t}-1)} \sim \mathrm{IN}\left(\Gamma w_{\mathrm{t}}, \Sigma\right)
$$

where $w_{\mathrm{t}} \subseteq s_{(\mathrm{t}-1)}$, and $\Gamma$ is a matrix of unrestricted parameters. This model may, but need not have, an economic interpretation as it is purely instrumental in the method used to derive the WET statistics.

From (3.1) and (3.4), the completed model $M_{1}^{c}=\left(M_{1}, M_{c}\right)$ is a vector autoregressive; (VAR) process in $s_{\mathrm{t}}$. Let $\boldsymbol{\alpha}$ denote the complete set of parameters of $\mathrm{M}_{1}^{\mathrm{c}}$ : $\boldsymbol{\alpha}=\left(\boldsymbol{\beta}, \boldsymbol{\sigma}^{2}, \Gamma, \Sigma\right)$ and suppose that they ensure the stationarity of $\mathrm{M}_{1}^{\mathrm{c}}$. The notation matches that of section 2, in that $\alpha$ denotes the parameters of the augmented $\mathrm{M}_{1}$ model needed to derive the predicted values of the statistics in $\mathrm{M}_{2}$ when there is feedback from the dependent variable onto the conditioning variables of either model. Two reformulations can be given for $M_{1}^{c}$; first, the Markovian representation (i.e. the companion form):

$$
\mathrm{M}_{1}^{\mathrm{c}}: f_{\mathrm{t}} \mid f_{\mathrm{t}-1} \sim \operatorname{IN}\left(\Pi(\alpha) f_{\mathrm{t}-1}, \Omega(\alpha)\right)
$$

where $\Pi(\alpha)$ and $\Omega(\alpha)$ are known functions of $\alpha$. Secondly, the marginal distribution of $f_{t}$ :

$$
\mathrm{M}_{1}^{\mathrm{c}}: f_{\mathrm{t}} \sim \mathrm{N}(0, \Psi(\alpha))
$$

where $\Psi(\alpha)=\Omega(\alpha)+\Pi(\alpha) \Psi(\alpha) \Pi(\alpha)^{\prime}$ is the marginal variance-covariance matrix of the variables evaluated under $\mathrm{M}_{1}^{\mathrm{c}}$. The $\mathrm{ML}$ estimator of $\Psi(\alpha)$ is obtained by replacing $\alpha$ by ix and is denoted below by $\tilde{\Psi}=\Psi(\tilde{\boldsymbol{\alpha}})$. The unconditional variance-covariance matrix of any subvector of $f_{\mathrm{t}}$, such as $x_{\mathrm{t}}$, will be denoted by using corresponding subscripts such as $\Psi_{X X}$.

We complete the definitions of the models with some further notation: $\mathcal{H}$ denotes the class of stationary VAR processes of the form (3.5) where $\Pi$ and $\Omega$ are unrestricted, and $\mu_{1}$ is the sub-set of $\mu$ including only models for which $M_{1}$ is the process generating the $\left\{y_{t}\right\}$. 


\subsection{Derivation of WET statistics}

We now derive the WET statistics relative to $\tilde{\delta}=\left(\tilde{\gamma}, \tilde{\tau}^{2}\right)$ for (complete) encompassing of $\mathrm{M}_{2}$. The derivation is conceptually straightforward and technicalities are omitted unless they are essential for the development of the argument (see Govaerts [1987] for detailed derivations of the relevant expressions).

Encompassing methodology in conditional dynamic models requires that statistics an: explicitly derived under the joint model $M_{1}^{c}=\left(M_{1}, M_{c}\right)$ and not just under $M_{1}$. Because the completing model $M_{c}$ is instrumental in the analysis, it influences the values of the WET statistics and hence the outcomes of the tests. Consequently, a careful choice of $M_{c}$ is required. This is discussed in section 3.3.

The method is based on the following result in Hannan [1970]. Let $\boldsymbol{A}$ denote the: unconstrained estimator of the second-order moment matrix of $f_{t}$ :

$$
A=\frac{1}{T} \sum_{\mathrm{t}=1}^{T} f_{\mathrm{t}} f_{\mathrm{t}}^{\prime},
$$

then the asymptotic distribution of $\operatorname{vec} A$, on $\mathrm{M}_{1}^{\mathrm{c}}$, is given by:

$$
\sqrt{T} \operatorname{vec}(\boldsymbol{A}-\Psi(\boldsymbol{\alpha})) \stackrel{\mathrm{d}}{\mathrm{M}_{\mathrm{Y}}} \mathrm{N}(\mathbf{0}, \boldsymbol{\Phi}(\boldsymbol{\alpha})),
$$

where $\Phi(\alpha)$ is an expression in $\Psi(\alpha)$ which follows from Hannan's formulae. Govaerts [1988] proposes an algorithm for evaluating $\Phi(\alpha)$ which is based on a Jordan canonical form representation of the system (3.5). Since $\delta$ is a known function of $\boldsymbol{A}$, the encompassing differences:

$$
\tilde{\Delta}_{\delta}=\tilde{\delta}-\delta_{\tilde{\alpha}}=\left(\tilde{\gamma}-\gamma_{\tilde{\alpha}}, \tilde{\tau}^{2}-\tau_{\tilde{\alpha}}^{2}\right)
$$

are as follows. First:

$$
\tilde{\gamma}=\left(Z^{\prime} Z\right)^{-1} Z^{\prime} y \text { and } \gamma_{\alpha}=\Psi_{Z Z}^{-1} \Psi_{Z Y}=\Psi_{Z Z}^{-1} \Psi_{Z X} \beta \text {, }
$$

so that:

$$
\begin{aligned}
\tilde{\gamma}-\gamma_{\tilde{\alpha}} & =\left(Z^{\prime} Z\right)^{-1} Z^{\prime} y-\tilde{\Psi}_{Z Z}^{-1} \tilde{\Psi}_{Z X} \tilde{\beta} \\
& =\left(Z^{\prime} Z\right)^{-1} Z^{\prime} Q_{X} y+\left(\left(Z^{\prime} Z\right)^{-1} Z^{\prime} X-\tilde{\Psi}_{Z Z}^{-1} \tilde{\Psi}_{Z X}\right) \tilde{\beta} .
\end{aligned}
$$

Next:

$$
\tilde{\tau}^{2}=\frac{1}{T} y^{\prime} Q_{Z} y
$$

and: 


$$
\begin{aligned}
\tau_{\alpha}^{2} & =\Psi_{Y Y}-\Psi_{Y Z} \Psi_{Z Z}^{-1} \Psi_{Z Y} \\
& =\sigma^{2}+\beta^{\prime} \Psi_{X X} \beta-\beta^{\prime} \Psi_{X Z} \Psi_{Z Z}^{-1} \Psi_{Z X} \beta \\
& =\sigma^{2}+\boldsymbol{\beta}^{\prime} \Psi_{X X \cdot Z} \boldsymbol{\beta},
\end{aligned}
$$

so that $\tau_{\alpha}^{2} \geq \sigma^{2}$, showing that variance dominance remains necessary. Further:

$$
\tilde{\tau}^{2}-\tau_{\tilde{\alpha}}^{2}=-\frac{1}{T}(y+X \tilde{\boldsymbol{\beta}})^{\prime} Z\left(Z^{\prime} Z\right)^{-1} Z^{\prime} Q_{X} y+\tilde{\boldsymbol{\beta}}^{\prime}\left(\frac{1}{T} X^{\prime} Q_{Z} X-\tilde{\Psi}_{X X} \cdot Z\right) \tilde{\boldsymbol{\beta}} .
$$

Compared to (2.9) and (2.10), these expressions show that the difference between the dynamic and static case is principally based on the values of the differences:

$$
\begin{aligned}
& D_{\gamma}=\left(Z^{\prime} Z\right)^{-1} Z^{\prime} X-\tilde{\Psi}_{Z Z}^{-1} \tilde{\Psi}_{Z X} ; \\
& D_{\tau^{2}}=\frac{1}{T} X^{\prime} Q_{Z} X-\tilde{\Psi}_{X X \cdot Z}
\end{aligned}
$$

or, collecting these together in a sufficient (but not necessary) formulation:

$$
D=\frac{1}{T}\left[\begin{array}{ll}
X^{\prime} \boldsymbol{X} & \boldsymbol{X}^{\prime} Z \\
Z^{\prime} \boldsymbol{X} & Z^{\prime} Z
\end{array}\right]-\left[\begin{array}{ll}
\tilde{\Psi}_{X X} & \tilde{\Psi}_{X Z} \\
\tilde{\Psi}_{Z X} & \tilde{\Psi}_{Z Z}
\end{array}\right] .
$$

This is the difference between an unrestricted estimator of the joint regressor second moment matrix, and an estimator thereof restricted by the implications from $M_{1}$ for the dynamic behaviour of the regressors. For testing parsimonious encompassing of $M_{1}$ against $M_{n}, Z$ is replaced by the total set of regressors $(\boldsymbol{X}, \boldsymbol{Z})$ in the previous formulae. In that case, all the formulae can be simplified, since projecting $\boldsymbol{X}$ on $\overline{\boldsymbol{Z}}=(\boldsymbol{X}, \boldsymbol{Z})$ ensures that:

$$
\left(\bar{Z}^{\prime} \bar{Z}\right)^{-1} \overline{\boldsymbol{Z}}^{\prime} \boldsymbol{X}=\tilde{\Psi}_{Z Z}^{-1} \tilde{\Psi}_{Z X}=(\boldsymbol{I}: 0) \text { and } \frac{1}{T} \boldsymbol{X}^{\prime} Q_{Z} X=\tilde{\Psi}_{X X \cdot Z}=0 \text {. }
$$

Thus, in nested models with valid completing assumptions, encompassing differences ar: identical in static and dynamic cases, but that does not imply the equality of the corresponding WET statistics as shown below.

The formula to derive $\mathrm{V}_{\alpha}\left[\sqrt{T}\left(\tilde{\delta}-\delta_{\tilde{\alpha}}\right)\right]=\mathrm{V}_{\alpha}\left[\sqrt{T} \tilde{\Delta}_{\delta}\right]$ follows from the fact that $\tilde{\Delta}_{\delta}$ as a function of $\tilde{\boldsymbol{\alpha}}$ and $\tilde{\boldsymbol{\delta}}$, is a known, continuous and differentiable function of $\boldsymbol{A}$ in (3.7):

$$
\tilde{\Delta}_{\delta}=\boldsymbol{h}(A) \text {. }
$$

Hence, the asymptotic distribution of $\tilde{\Delta}_{\delta}$ on $M_{1}^{c}$ is given by:

$$
\sqrt{T} \tilde{\Delta}_{\delta} \overrightarrow{\mathrm{M}}_{\mathrm{Y}}^{\mathrm{d}} \mathrm{N}\left(0, \boldsymbol{H}(\boldsymbol{\alpha}) \Phi(\boldsymbol{\alpha}) \boldsymbol{H}(\boldsymbol{\alpha})^{\prime}\right),
$$

where $\boldsymbol{H}(\alpha)=\operatorname{plim}_{\alpha}\left(\partial \boldsymbol{h}(\boldsymbol{A}) / \partial \mathrm{vec} \boldsymbol{A}^{\prime}\right)$. Analytical evaluation of $\boldsymbol{H}(\boldsymbol{\alpha})$ is impractical for most models (even simple ones) but its numerical evaluation is general and based on elementary 
matrix operations. Nevertheless, under restricted conditions (detailed below) the analytical expression of $\mathrm{V}_{\alpha}\left[\sqrt{T} \tilde{\Delta}_{\delta}\right]$ is known, or almost known, and a direct comparison with the static case can be made.

\subsection{Choice of the completing model}

The choice of different completing models in the comparison of $M_{1}$ to $M_{2}$ can lead to different expressions for $\tilde{\Psi}, D_{\gamma}, D_{\tau^{2}}, D$, and hence can affect the encompassing statistics, occasionally inducing different conclusions for the corresponding encompassing tests. Consequently, the issue of robustness of the encompassing analysis against alternative choices of $M_{c}$ arises. The orders in probability of the differences $D_{\gamma} D_{\tau^{2}}, D$ are at the root of the discussion. If $\boldsymbol{D}=0$, the WET will be equivalent to the $F$-test; when $\boldsymbol{D} \neq 0$, different cases must be studied. Six cases are retained, corresponding to the possible values of th: encompassing differences, and the following concepts are defined:

(i) $\quad M_{1}^{c}$ is exactly moment efficient (EME) against $M_{2}$ iff $D=0$;

(ii) $\quad \mathrm{M}_{1}^{\mathrm{c}}$ is exactly projection efficient (EPE) against $\mathrm{M}_{2}$ iff $D_{\gamma}=0$ and $\boldsymbol{D}_{\tau^{2}}=0$;

(iii) $\quad \mathrm{M}_{1}^{\mathrm{c}}$ is strongly moment efficient (SME) against $\mathrm{M}_{2}$ iff $\underset{\mathcal{H}}{D} \approx 0$;

(iv) $\quad \mathrm{M}_{1}^{\mathrm{c}}$ is strongly projection efficient (SPE) against $\mathrm{M}_{2}$ iff $D_{\gamma} \approx 0$ and $D_{\tau^{2}} \approx 0$;

(v) $\quad M_{1}^{c}$ is weakly moment efficient (WME) against $M_{2}$ iff $D \simeq 0$;

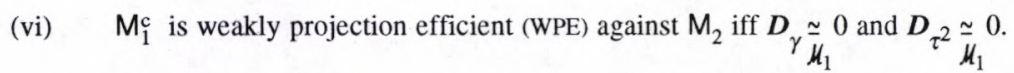

These concepts are related to each other as summarized in proposition 3.1:

Proposition 3.1:

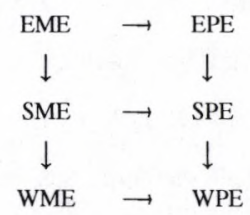

There are counter examples showing that no other relation exists between these concepts.

If none of the properties in (i)-(vi) holds, the robustness of the corresponding WE ${ }^{\text {- }}$ statistics is seriously compromised. In fact, if either of:

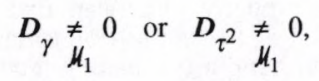


then there exists at least one $\left(\mathrm{M}_{1}, \mathrm{M}_{\mathrm{c}}^{*}\right) \in \mathcal{M}_{1}$ such that $\operatorname{plim}_{\alpha} \tilde{\Delta}_{\gamma} \neq 0$ or $\operatorname{plim} \tilde{\alpha}_{\tau^{2}} \neq 0$ under $\left(M_{1}, M_{c}^{*}\right)$. As a consequence, when $M_{c}$ is mis-specified, $M_{1}^{c}$ can fail to encompass $M_{2}$ despite the fact that $M_{1}$ is the true model: example 4.7 illustrates this phenomenon. Fortunately, wPE can always be achieved as stated in proposition 3.2.

Proposition 3.2: For any pair of rival models $\mathrm{M}_{1}$ and $\mathrm{M}_{2}$ of the form (3.1) and (3.2), there exists at least one completing model $\mathrm{M}_{\mathrm{c}}$ such that $\mathrm{M}_{1}$ is WME and WPE against $\mathrm{M}_{2}$.

A sufficient condition to ensure WME (and so WPE) is that $\operatorname{plim} \boldsymbol{D}=\mathbf{0}$, so $\mathrm{M}_{1}^{\mathrm{c}}$ must generate the correct number and type of second moments of the joint set of regressors, which requires that $M_{1}^{c}$ include a sufficiently rich dynamic specification. Parsimonious encompassing automatically ensures minimal robustness for WET statistics:

Proposition 3.3: If $\mathrm{M}_{1} \subset \mathrm{M}_{2}$, then $\mathrm{M}_{1}^{\mathrm{c}}$ is EPE against $\mathrm{M}_{2}$ for any choice of completing model $\mathrm{M}_{\mathrm{c}}$.

More important are the properties of the WET statistics for the different possible values of $D_{\gamma} D_{\tau^{2}}$ and $D$ summarized in proposition 3.4 .

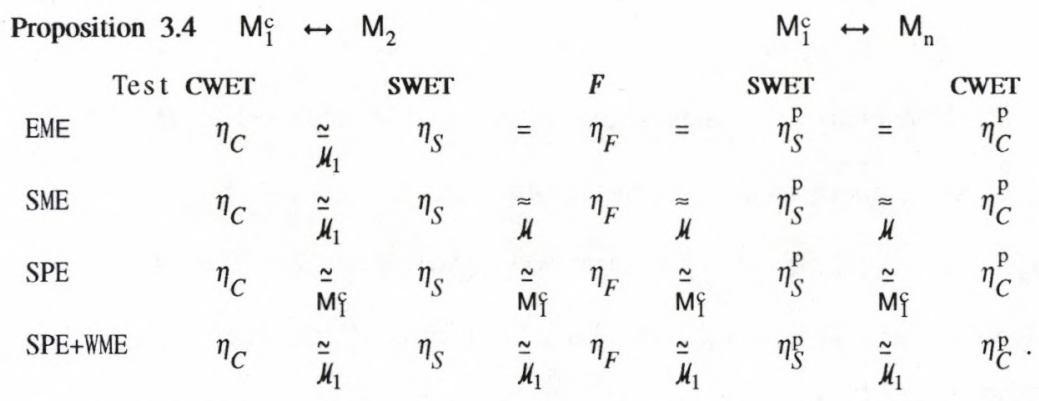

In every case, the WET statistics are analytically known and are easily computed. The first row (EME) directly generalizes (2.11) to dynamic models; SME ensures strong asymptotic equivalence under $\mathcal{M}$ across all the tests; SPE only delivers weak asymptotic equivalencis under $\mathrm{M}_{1}^{\mathrm{c}}$; but SPE and WME together deliver weak asymptotic equivalence under $\mathcal{H}$.

The important question is whether or not, given a pair of models $M_{1}$ and $M_{2}$, there exists a completing model $M_{c}$ that ensures SPE or a stronger property. Unfortunately, such a model does not always exist, and as stated in proposition 3.2 , the best property which can always be achieved is WME. Following Govaerts [1987], an algorithm to build a completing model 
for a given pair of models $M_{1}, M_{2}$, based on a systematic comparison of the two lists of regressors in $M_{1}$ and $M_{2}$, is described in the appendix. The outcome is a list of regressors defining a minimal completing model, denoted here by $\mathrm{M}_{\mathrm{c}}^{\mathrm{m}}$, with a number of features:

If $M_{1}$ and $M_{2}$ are such that there exists a completing model $M_{c}$ under which $\left(M_{1}, M_{c}\right)$ is EME (or SME), then $\left(M_{1}, M_{c}^{m}\right)$ is EME (or SME);

(ii) The model $\left(M_{1}, M_{c}^{m}\right)$ is always WME and, hence, WPE;

(iii) $\quad \mathrm{M}_{\mathrm{c}}^{\mathrm{m}}$ is minimal in that its list of regressors is included in the list associated with any other model $M_{c}$ that satisfies EME, SME or WME.

(iv) If there exists a model $M_{c}$ for which SPE is achieved, it will be nested in $M_{c}^{m}$ but the latter will not necessarily be SPE.

(v) The minimal completing model is invariant to the choice of rival model $M_{n}^{*}$ nesting $M_{2}^{\perp}$ and nested in $M_{n}$.

It follows that, unless the proprietor of $M_{1}$ has particular reasons for selecting a specific completing model $\mathbf{M}_{\mathrm{c}}$, selecting $\mathbf{M}_{\mathrm{c}}^{\mathrm{m}}$ as the completing model achieves robustness within the class of VAR completing models. Other choices for $M_{c}$ need not achieve even this minimal property. Finally, based on the appendix algorithm, a sufficient condition for SME is available which does not need any additional calculations to check if $M_{1}^{c}$ is SME:

Proposition 3.5 If $(i)$ the number of parameters of $\left(\mathrm{M}_{1}, \mathrm{M}_{\mathrm{c}}\right)$ is equal to the number of data second-order moments used in the evaluation of the estimators of these parameters (neglecting terms of $\mathrm{O}_{\mathrm{p}}\left(\frac{1}{T}\right)$ ); and (ii) all the cross products included in $\frac{1}{T} X^{\prime} \boldsymbol{X}, \frac{1}{T} \boldsymbol{X}^{\prime} \boldsymbol{Z}$ and $\frac{1}{T} \boldsymbol{Z}^{\prime} \boldsymbol{Z}$ appear in the estimators of the parameters of $\mathrm{M}_{1}^{\mathrm{c}}$,

then $\left(\mathrm{M}_{1}, \mathrm{M}_{\mathrm{c}}\right)$ is SME against $\mathrm{M}_{2}$.

Intuitively, the stated conditions ensure that $D$ is at most $\mathrm{O}_{\mathrm{p}}\left(\frac{1}{T}\right)$ for all members of $\mu$, which in turn was shown above to entail SME.

\subsection{Power Comparisons}

Although proposition 3.4 relates the various tests $\eta_{C}, \eta_{S}, \eta_{F}, \eta_{S}^{\mathrm{p}}$ and $\eta_{C}^{\mathrm{p}}$ under the null, it does not follow that they have the same power properties when $M_{1}$ is false. In particular, care is required in formulating the maintained hypothesis within which power is studied. 
There are three distinct ways in which $M_{1}$ might be mis-specified relative to the assumed DGP. First, the alternative (denoted $M_{a}$ ) may differ from $M_{1}$ in the direction of $M_{2}$ but retain elements of $M_{1}$; second, $M_{a}$ could be $M_{2}$ itself; finally, none of the elements in either $M_{1}$ or $M_{2}$ may be present in $M_{a}$. In each case, to correctly evaluate the power, $M_{1}$ must remain congruent with the data evidence despite being mis-specified, and in the context of dynamic models this aspect is not easy to achieve.

When $M_{a}$ corresponds to $M_{n}$ (e.g. the union of $M_{1}$ and $M_{2}$ less any redundant elements), then the $F$-test is bound to have the highest power in large samples since its error will be an innovation with minimum variance in the class, whereas $M_{1}$ will fail to have an innovation error if $M_{2}$ is dynamic. However, tests for innovation errors seem more appropriate for such a scenario than the encompassing tests discussed here. Example 4.2 illustrates this, and points up the advantages of parsimonious encompassing tests and general-to-simple modelling strategies.

When $M_{a}$ does not correspond to $M_{n}$, power rankings are less clear-cut, and in small samples may depend on degrees of freedom. Example 4.3 illustrates this case.

4.

EXAMPLES

The aim of this section is to illustrate the concepts and properties defined above using some simple examples. The choice of the completing model is discussed, explicit forms of the WET differences and statistics are given, most of the possible cases of moment and projection efficiency are illustrated, and the minimal completing model is given for each example. The $F$-test against $M_{n}$ is asymptotically valid (i.e. it has the correct size asymptotically and is consistent against fixed alternatives), and is the parsimonious encompassing statistic.

\section{Example 4.1: The static case}

Static linear models were formulated in section 2 as:

$\mathrm{M}_{1}: y_{\mathrm{t}}=\boldsymbol{\beta}^{\prime} x_{\mathrm{t}}+\varepsilon_{1 \mathrm{t}}$ with the claim that $\varepsilon_{1 \mathrm{t}} \sim \mathrm{IN}\left(0, \sigma_{1}^{2}\right)$;

$\mathrm{M}_{2}: y_{\mathrm{t}}=\gamma^{\prime} z_{\mathrm{t}}+\varepsilon_{2 \mathrm{t}}$ with the claim that $\varepsilon_{2 \mathrm{t}} \sim \operatorname{IN}\left(0, \sigma_{2}^{2}\right)$. 
The minimal completing model derived from the algorithm is simply and minimally the unrestricted white-noise process:

$\mathrm{M}_{\mathrm{c}}^{\mathrm{m}}: w_{\mathrm{t}}=u_{\mathrm{t}}$ where $u_{\mathrm{t}} \sim \mathbb{I N}(0, \Sigma)$ when $w_{\mathrm{t}}^{\prime}=\left(x_{\mathrm{t}}^{\prime}, z_{\mathrm{t}}^{\prime}\right)$.

EME, EPE etc. are verified in this case since, for example, $\Psi_{W W}=\operatorname{plim}_{\alpha} T^{-1} W^{\prime} W=\Sigma$ and $\tilde{\boldsymbol{\Phi}}_{W W}=\mathcal{\Sigma}=T^{-1} W^{\prime} \boldsymbol{W}$, so that $\boldsymbol{D}=\mathbf{0}$. The results given in proposition 3.4 apply and coincide with those given in proposition 2.1. However, as discussed in section 1, invalidly restricting $\sum$ can lead to rejection of $M_{1}$ even when it is the DGP.

$M_{c}^{m}$ can be written in an equivalent projection form for the conditional distribution of $x_{t}$ given $z_{\mathrm{t}}$, jointly with the marginal process for $z_{\mathrm{t}}$ :

$$
\begin{array}{rlrl}
M_{\mathrm{c}}^{\mathrm{m}_{*}^{*}: x_{\mathrm{t}}} & =\pi z_{\mathrm{t}}+u_{1 \mathrm{t}}^{*} & \text { where } & u_{1 \mathrm{t}}^{*} \sim \operatorname{IN}\left(0, \Sigma_{X X} \cdot Z\right) ; \\
z_{\mathrm{t}} & =u_{2 \mathrm{t}} \quad \text { with } & u_{2 \mathrm{t}} \sim \operatorname{IN}\left(0, \Sigma_{Z Z}\right),
\end{array}
$$

where $\pi=\Sigma_{X Z} \sum_{Z Z}^{-1}$ and $\boldsymbol{u}_{1 \mathrm{t}}^{*} \perp \boldsymbol{u}_{2 \mathrm{v}}$. The first part of $\mathrm{M}_{\mathrm{c}}^{\mathrm{m}^{*}}$ is the completing model used by Hendry and Richard [1983] to introduce the encompassing principle in the static case. They show that defining the projection of $x_{t}$ on $z_{t}$ in this way is sufficient to ensure EPE to $M_{1}$. We have:

$$
\begin{aligned}
& \Psi_{Z Z}^{-1} \Psi_{Z X}=\Sigma_{Z Z}^{-1} \Sigma_{Z X}=\pi^{\prime} \quad \text { and } \quad \tilde{\pi}^{\prime} \quad=\left(Z^{\prime} Z\right)^{-1} Z^{\prime} X \\
& \boldsymbol{\Psi}_{\boldsymbol{X} \boldsymbol{X} \cdot \boldsymbol{Z}}=\Sigma_{X X \cdot Z} \quad \text { and } \quad \tilde{\Sigma}_{X X \cdot Z}=\frac{1}{\boldsymbol{T}^{\prime}} \boldsymbol{Q}_{Z} \boldsymbol{X},
\end{aligned}
$$

so that only strong exogeneity needs to be postulated for the marginal process of $z_{\mathrm{t}}$. This claim remains true even if in fact $z_{t}$ is Granger-caused by $y$, so complete robustness is achieved.

\section{Example 4.2: Autoregressive models}

Reconsider the simple dynamic model from section 1 :

$\mathrm{M}_{1}: \quad y_{\mathrm{t}}=\beta y_{\mathrm{t}-1}+\varepsilon_{1 \mathrm{t}}$ where $\varepsilon_{1 \mathrm{t}} \sim \mathrm{IN}\left(0, \sigma^{2}\right)$;

$\mathrm{M}_{2}: y_{\mathrm{t}}=\gamma_{\mathrm{t}-2}+\varepsilon_{2 \mathrm{t}} \quad$ with $\quad \varepsilon_{2 \mathrm{t}} \sim \operatorname{IN}\left(0, \tau^{2}\right)$,

such that $|\beta|<1$. Then, $M_{1}$ is itself the completing model, and we have:

$$
\Psi_{Z X}=\operatorname{plim}_{\alpha} \frac{1}{T} \boldsymbol{y}_{-2}^{\prime} \boldsymbol{y}_{-1}=\beta \sigma^{2} /\left(1-\beta^{2}\right),
$$

where (e.g.) $y_{-1}^{\prime}=\left(y_{2} \ldots y_{\mathrm{T}-1}\right)$, and:

$$
\Psi_{Z Z}=\operatorname{plim}_{\alpha} \frac{1}{T} y_{-2}^{\prime} y_{-2}=\left[\sigma^{2} /\left(1-\beta^{2}\right)\right]=\Psi_{X X} ;
$$


so that $\tilde{\Psi}_{Z Z}^{-1} \tilde{\Psi}_{Z X}=\tilde{\beta}$, and hence the restricted second moments are determined by $M_{1}$ alone. Thus:

$$
\begin{aligned}
\left(Z^{\prime} Z\right)^{-1} Z^{\prime} X & =\left(y_{-2}^{\prime} y_{-2}\right)^{-1} y_{-2}^{\prime} y_{-1}=\tilde{\beta}+O_{p}\left(\frac{1}{T}\right) \\
& =\left(y_{-1}^{\prime} y_{-1}\right)^{-1} y_{-1}^{\prime} y+O_{p}\left(\frac{1}{T}\right),
\end{aligned}
$$

where the terms of $\mathrm{O}_{\mathrm{p}}\left(\frac{1}{T}\right)$ are due to lagging. Similarly:

$$
\frac{1}{T} X^{\prime} Q_{Z} \boldsymbol{X}=\tilde{\Psi}_{X X . Z}+\mathrm{O}_{\mathrm{p}}\left(\frac{1}{T}\right),
$$

and hence $M_{1}$ is SPE against $M_{2}$. One can show that $M_{1}$ is also SME on replacing $\beta$ and $\sigma^{2}$ by their estimators in the above formulae. This result guarantees that, in this simple dynamic case, the WET statistics are equivalent to the $F$-statistic as stated in proposition 3.4.

If we switch the two competing models so the rival models become:

$\mathrm{M}_{1}^{\dagger}: y_{\mathrm{t}}=\beta y_{\mathrm{t}-2}+\varepsilon_{1 \mathrm{t}}$

$\mathrm{M}_{2}^{\dagger}: y_{\mathrm{t}}=w_{\mathrm{t}-1}+\varepsilon_{2 \mathrm{t}}$,

then the forms of the statistics change noticeably and $M_{1}^{\dagger}$ is no longer SME but only WMI. This example illustrates the differences that can occur between $\eta_{F}, \eta_{S}$ and $\eta_{S}^{\mathrm{p}}$ when including lagged dependent variables in the list of regressors. The WET statistics can be evaluated (unconditionally on the regressors) either directly or by taking advantage of the general technique discussed in section 3.2 above. The completing model is now $\mathrm{M}_{2}^{\dagger}$ and the complete encompassing differences relative to the parameters of $M_{2}^{\dagger}$ and $M_{n}$ (define $u^{i}$ is. section 1) are:

$$
\begin{aligned}
& \tilde{\Delta}_{\delta}=\left(1:-\frac{1}{T} y^{\prime} y_{-1}\right)^{\prime}\left(y^{\prime} y\right)^{-1} y^{\prime} y_{-1} \\
& \tilde{\Delta}_{d}=\left(1:-\frac{1}{T}\left(y^{\prime} y\right)^{-1} y^{\prime} y_{-1}:-\frac{1}{T} y^{\prime} Q_{y_{-2}} y_{-1}\right)^{\prime}\left(y^{\prime} Q_{y_{-1}} y\right)^{-1} y^{\prime} Q_{y_{-2}} y_{-1}
\end{aligned}
$$

where $Q_{y_{-i}}=I_{T}^{-y_{-i}}\left(y_{-i}^{\prime} y_{-i}\right)^{-1} y_{-i}^{\prime}$.

The variance-covariance matrices of $\tilde{\Delta}_{\delta}$ and $\tilde{\Delta}_{d}$ on $\mathrm{M}_{1}$ are both singular of rank 1 and so.

$$
\begin{aligned}
& \eta_{C}=\tilde{\sigma}^{-2}\left(y^{\prime} Q_{\mathrm{y}_{-2}} y_{-1}\right)^{2}\left(y^{\prime} y\right)^{-1} \stackrel{\mathrm{d}}{\overrightarrow{\mathrm{M}}_{1}} \chi^{2}(1) \\
& \eta_{C}^{\mathrm{p}}=\tilde{\sigma}^{-2}\left(y^{\prime} Q_{\mathrm{y}_{-2}} y_{-1}\right)^{2}\left(y^{\prime} Q_{\mathrm{y}_{-1}} y\right)^{-2} y^{\prime} y \stackrel{\mathrm{d}}{\overrightarrow{\mathrm{M}}_{1}} \chi^{2(1)} \\
& \eta_{F}=\tilde{\sigma}^{-2}\left(y^{\prime} Q_{\mathrm{y}_{-2}} y_{-1}\right)^{2}\left(y^{\prime} Q_{\mathrm{y}_{-1}} y\right)^{-1} \frac{\mathrm{d}}{\overrightarrow{\mathrm{M}}_{1}} \chi^{2}(1) .
\end{aligned}
$$

In this example, the three statistics are ordered as $\eta_{C} \leq \eta_{F} \leq \eta_{C}^{\mathrm{p}}$. They are asymptotically 
equivalent on any model for which $T^{-1} y^{\prime} y_{-1} \stackrel{p}{\rightarrow} 0$ as $T \rightarrow \infty$ (i.e., in particular on $M_{1}$ or on local alternatives to $M_{1}$ which do not introduce first-order autocorrelation). An interesting difference between the two orderings of the hypotheses here is that the implicit projection of the $F$-test switches from the realizable dynamic model $y_{\mathrm{t}}=\phi y_{\mathrm{t}-1}+u_{\mathrm{t}}$ to the forward projection of $y_{\mathrm{t}-2}$ on $y_{\mathrm{t}-1}$, although $\mathrm{M}_{\mathrm{c}}^{\mathrm{m}}$ remains the same.

Govaerts [1987] examined the power of the three statistics in (4.9)-(4.11) by Monte Carlo simulations under local alternatives to $M_{1}$ of the form:

$$
y_{\mathrm{t}}=T^{\frac{1}{2}} v_{1} y_{\mathrm{t}-1}+v_{2} y_{\mathrm{t}-2}+\zeta_{\mathrm{t}}=\theta y_{\mathrm{t}-1}+v_{2} y_{\mathrm{t}-2}+\zeta_{\mathrm{t}} \text { where } \zeta_{\mathrm{t}} \sim \operatorname{IN}\left(0, \sigma_{\zeta}^{2}\right) \text {. }
$$

After correction for size, $\eta_{C}$ turns out to have lower finite sample power than either $\eta_{F}$ or $\eta_{C}^{\mathrm{p}}$. The asymptotic power functions for $\eta_{C}$ and $\eta_{F}$ under the local alternative in (4.12) can be derived as follows. First, the plims of the data second moments under (4.12) are:

$$
\begin{aligned}
& \Sigma_{\mathrm{yy}}=\left(1-v_{2}\right) \sigma_{\zeta}^{2} /\left[\left(1+v_{2}\right)\left\{\left(1-v_{2}\right)^{2}-\theta^{2}\right\}\right] ; \quad \Sigma_{\mathrm{yy}}=\theta \Sigma_{\mathrm{yy}} /\left(1-v_{2}\right) ; \text { and: } \\
& \Sigma_{\mathrm{yy}_{-2}}=\left[v_{2}\left(1-v_{2}\right)+\theta^{2}\right] \Sigma_{\mathrm{yy}} /\left(1-v_{2}\right) .
\end{aligned}
$$

Estimation of $M_{1}$ leads to population parameter values $\beta_{\mathrm{p}}=\operatorname{plim} \tilde{\beta}$, and $\sigma_{\mathrm{p}}^{2}=$ plim $\tilde{\sigma}^{2}$ :

$$
\beta_{\mathrm{p}}=\Sigma_{\mathrm{yy}}^{-1 \Sigma_{\mathrm{yy}}-2}=\left[v_{2}\left(1-v_{2}\right)+\theta^{2}\right] /\left(1-v_{2}\right)
$$

and:

$$
\sigma_{\mathrm{p}}^{2}=\sigma_{\zeta}^{2}\left(1+\left[\left(1-v_{2}\right) \theta^{2} /\left(1+v_{2}\right)\left\{\left(1-v_{2}\right)^{2}-\theta^{2}\right\}\right]\right) .
$$

On local alternatives like (4.12), the $\eta_{\bullet}$ tests become non-central $\chi^{2}\left(1, \mu^{2}\right)$ where (see Mizon and Hendry, 1980):

$$
\begin{aligned}
\mu^{2}\left(\eta_{F}\right)= & v_{1}^{2} /\left(1-v_{2}^{2}\right)=T \theta^{2} /\left(1-v_{2}^{2}\right) \\
\mu^{2}\left(\eta_{C}\right) & =\sigma_{\zeta}^{2} v_{1}^{2}\left\{\left(1-v_{2}\right)^{2}-\theta^{2}\right\} / \sigma_{\mathrm{p}}^{2}\left(1-v_{2}^{2}\right)\left(1-v_{2}\right)^{2} \\
& =\mu^{2}\left(\eta_{F}\right)\left[1-2 \theta^{2} /\left(1-v_{2}^{2}\right)\left(1-v_{2}\right)\right]+o\left(T^{-1}\right) \leq \mu^{2}\left(\eta_{F}\right) .
\end{aligned}
$$

Two factors contribute to the power loss arising from the smaller non-centrality parameter: on (4.12), $\sigma_{\mathrm{p}}^{2} \geq \sigma_{\zeta}^{2}$, which $\eta_{F}$ avoids; and $\beta_{\mathrm{p}} \neq \beta$, so the residuals in $\mathrm{M}_{1}$ are not white noise, whereas $\left\{\zeta_{t}\right\}$ is, so $M_{1}$ ceases to be congruent and is not a good basis for testing. Even though $\theta$ is $\mathrm{O}\left(T^{-\frac{1}{2}}\right)$, the asymptotic power loss is quite large as figure 1 show"; for the parameter values $\theta=0.1$, and $v_{2}=0.8$ over $T=70, \ldots, 300$. The small sample power of the $F$-test is also shown, based on recursive Monte Carlo using PC-NAIVE (see Hendry, Neale and Ericsson, 1991), to illustrate the applicability of the asymptotic formulae. 


\section{Example 4.3: Strong moment efficiency (SME)}

Let the two rival models be:

$\mathrm{M}_{1}: y_{\mathrm{t}}=\beta x_{\mathrm{t}}+\varepsilon_{1 \mathrm{t}}$

$\mathrm{M}_{2}: y_{\mathrm{t}}=\gamma_{\mathrm{t}-1}+\varepsilon_{2 \mathrm{t}}$,

with the usual claims that $\varepsilon_{\mathrm{it}} \sim \operatorname{IN}\left(0, \sigma_{\mathrm{i}}^{2}\right)$. It seems natural to consider as a completing model, the realizable projection model:

$\mathrm{M}_{\mathrm{c}}^{\mathrm{m}}: x_{\mathrm{t}}=\phi y_{\mathrm{t}-1}+u_{\mathrm{t}}$ where $u_{\mathrm{t}} \sim \mathrm{IN}\left(0, \tau^{2}\right)$.

The appendix algorithm for the minimal completing model also yields $M_{c}^{m}$.

Verifying that $M_{1}^{c}$ is SME in this case is tedious if one wants to explicitly calculate the order of the difference $\boldsymbol{D}$ in section 3.3(i)-(vi) above, but fortunately the sufficient condition for SME in proposition (3.5) is applicable. The number of parameters in $M_{1}^{c}$ is four: $\beta, \sigma^{2}, \phi$, $\tau^{2}$. The data second-order moments used in their estimation are $\frac{1}{T} x^{\prime} x, \frac{1}{T} x^{\prime} y_{-1}, \frac{1}{T} y^{\prime} y$ and $\frac{1}{T} x^{\prime} y$ and hence, condition (i) is verified. Second, in present notation, the cross products appearing in $\frac{1}{T} X^{\prime} X, \frac{1}{T} X^{\prime} Z$, and $\frac{1}{T} Z^{\prime} Z$ are $\frac{1}{T} x^{\prime} x, \frac{1}{T} x^{\prime} y_{-1}$ and $\frac{1}{T} y^{\prime} y$ which ensures that (ii) is satisfied. $M_{1}^{c}$ is then SPE and the equivalences between WET and $F$-statistics given in proposition 3.4 hold.

If we switch the rival models:

$\mathrm{M}_{1}^{\dagger}: y_{\mathrm{t}}=\beta \dot{y_{\mathrm{t}-1}}+\varepsilon_{1 \mathrm{t}}$ where $\varepsilon_{1 \mathrm{t}} \sim \mathrm{IN}\left(0, \sigma_{1}^{2}\right)$

$\mathrm{M}_{2}^{\dagger}: y_{\mathrm{t}}=\gamma x_{\mathrm{t}}+\varepsilon_{2 \mathrm{t}} \quad$ where $\varepsilon_{2 \mathrm{t}} \sim \mathrm{IN}\left(0, \sigma_{2}^{2}\right)$,

the completing model remains the projection model $M_{c}^{m}$ above. Consider the locai alternative:

$\mathrm{M}_{\mathrm{a}}: y_{\mathrm{t}}=\lambda_{1} y_{\mathrm{t}-1}+\lambda_{2} z_{\mathrm{t}}+\zeta_{\mathrm{t}}$ where $\zeta_{\mathrm{t}} \sim \operatorname{IN}\left(0, \sigma_{\zeta}^{2}\right)$,

when:

$$
z_{\mathrm{t}}=\rho x_{\mathrm{t}}+v_{\mathrm{t}} \text { with } v_{\mathrm{t}} \sim \mathbb{I N}\left(0, \sigma_{v}^{2}\right)
$$

In this example, direct substitution of (4.17) into $M_{a}$ shows that $\beta$ and $\varepsilon_{1 t}$ in $M_{1}^{\dagger}$ are:

$$
\beta=\left(\lambda_{1}+\lambda_{2} \rho \phi\right) \text { and } \varepsilon_{1 \mathrm{t}}=\left(\zeta_{\mathrm{t}}+\lambda_{2} v_{\mathrm{t}}+\lambda_{2} \rho \mathrm{u}_{\mathrm{t}}\right) \text {, }
$$

whereas $e_{\mathrm{t}}$ in $\mathrm{M}_{\mathrm{n}}$ is $\left(\zeta_{\mathrm{t}}+\lambda_{2} v_{\mathrm{t}}\right)$, so that the asymptotic non-centrality of the $F$-test is:

$$
\mu^{2}\left(\eta_{F}\right)=\left(\lambda \frac{2}{2} \rho^{2} \sigma_{u}^{2}\right) /\left(\lambda_{2}^{2} \sigma_{v}^{2}+\sigma_{\zeta}^{2}\right) .
$$

Further, the asymptotic encompassing difference is: 


$$
\operatorname{plim} \tilde{\Delta}_{\phi}=\operatorname{plim}\left(\tilde{\gamma} \boldsymbol{\gamma}_{\tilde{\alpha}}\right)=\lambda_{2} \rho \sigma_{\mathrm{u}}^{2} / \sigma_{\mathrm{x}}^{2},
$$

with a limiting variance of $\sigma_{\mathrm{u}}^{2}\left(\lambda_{2}^{2} \sigma_{v}^{2}+\sigma_{\zeta}^{2}\right) / \sigma_{\mathrm{x}}^{4}$, so that:

$$
\mu^{2}\left(\eta_{C}\right)=\left(\lambda_{2}^{2} \rho^{2} \sigma_{\mathrm{u}}^{2}\right) /\left(\lambda_{2}^{2} \sigma_{v}^{2}+\sigma_{\zeta}^{2}\right)
$$

and so the two tests are asymptotically equivalent under a local alternative that keeps $M_{1}^{\dagger}$ congruent.

The use of other completing models may generate WET statistics that satisfy neither strong projection nor moment efficiency conditions, and even worse choices can lose weak efficiency. For example, consider:

$\mathrm{M}_{\mathrm{c}}: x_{\mathrm{t}}=u_{\mathrm{t}}$

Under $\mathrm{M}_{1}^{\mathrm{c}}, \Psi_{X Z}=\Psi_{x y_{-1}}=0$, and the encompassing difference on $\gamma$ becomes:

$$
\tilde{\gamma}-\gamma_{\tilde{\alpha}}=\left(y_{-1}^{\prime} y_{-1}\right)^{-1} y_{-1}^{\prime} y
$$

from which $\eta_{S}$ can be derived. Since $M_{1}^{c}$ is neither WME nor WPE, there exists at least one $\mathrm{M}_{1}^{*}=\left(\mathrm{M}_{1}, \mathrm{M}_{\mathrm{c}}^{*}\right) \in \mathcal{M}_{1}$ such that $D_{\gamma_{\mathrm{M}_{1}}}^{\neq}$. If the DGP is $\left(\mathrm{M}_{1}, \mathrm{M}_{\mathrm{c}}^{*}\right)$ where:

$\mathrm{M}_{\mathrm{c}}^{*}: x_{\mathrm{t}}=\phi x_{\mathrm{t}-1}+u_{\mathrm{t}}$,

then $\eta_{S} \rightarrow \infty$ under the DGP when $T$ increases, and hence the WET will, in most cases, reject even though the model $M_{1}$ is correct. Such an outcome demonstrates the dangers of using inappropriate completing models and encourages the design of completing models with the aim of ensuring a minimum of robustness for the resulting WET statistics.

\section{Example 4.4: Exact projection efficiency (EPE)}

Let:

$$
\begin{aligned}
& \mathrm{M}_{1}: y_{\mathrm{t}}=\beta x_{\mathrm{t}}+\varepsilon_{1 \mathrm{t}} \\
& \mathrm{M}_{2}: y_{\mathrm{t}}=\gamma_{1} y_{\mathrm{t}-1}+\gamma_{2} y_{\mathrm{t}-2}+\varepsilon_{2 \mathrm{t}} .
\end{aligned}
$$

The minimal completing model is given by the projection of $x_{\mathrm{t}}$ on $y_{\mathrm{t}-1}$ and $y_{\mathrm{t}-2}$ : $\mathrm{M}_{\mathrm{c}}^{\mathrm{m}}: x_{\mathrm{t}}=\phi_{1} y_{\mathrm{t}-1}+\phi_{2} y_{\mathrm{t}-2}+u_{\mathrm{t}}$

Formulae (4.1) in example 1 can be applied to check that EPE is satisfied here. This does not imply the equality of the WET statistics with the $F$-statistic because $\mathrm{V}_{\alpha}[\sqrt{T} \tilde{\Delta}]$ differs from the corresponding matrix obtained in the static case. Nevertheless, from proposition 3.4, the encompassing statistics are $\tilde{\mu}_{1}$ to $\eta_{F}$ because the choice of the minimal completing 
model ensures that $M_{1}^{c}$ is also WME.

\section{Example 4.5: Strong projection efficiency (SPE)}

This example differs from the last in lagging the regressors of the two models by one period:

$\mathrm{M}_{1}: y_{\mathrm{t}}=\beta x_{\mathrm{t}-1}+\varepsilon_{1 \mathrm{t}}$

$\mathrm{M}_{2}: y_{\mathrm{t}}=\gamma_{1} y_{\mathrm{t}-2}+\gamma_{2} y_{\mathrm{t}-3}+\varepsilon_{2 \mathrm{t}}$

The projection model remains the same:

$\mathrm{M}_{\mathrm{c}}: x_{\mathrm{t}}=\phi_{1} y_{\mathrm{t}-1}+\phi_{2} y_{\mathrm{t}-2}+u_{\mathrm{t}}$

and is included in the minimal completing model given by:

$\mathrm{M}_{\mathrm{c}}^{\mathrm{m}}: x_{\mathrm{t}}=\phi_{1} y_{\mathrm{t}-1}+\phi_{2} y_{\mathrm{t}-2}+\phi_{3} y_{\mathrm{t}-3}+\phi_{4} x_{\mathrm{t}-1}+u_{\mathrm{t}}$

Then $\left(M_{1}, M_{c}\right)$ is SPE for the same reasons as before. The difference between EPE and SPE is due to lagging; for example, $\frac{1}{T} \boldsymbol{x}_{-1}^{\prime} \boldsymbol{y}_{-2}$ in $\left(\boldsymbol{Z}^{\prime} Z\right)^{-1} \boldsymbol{Z}^{\prime} \boldsymbol{X}$ is estimated by $\frac{1}{T} \boldsymbol{x}^{\prime} \boldsymbol{y}_{-1}$ in $\tilde{\boldsymbol{\Psi}}_{Z Z}^{-1} \tilde{\Psi}_{Z X}$

It can also be shown that WME is not achieved for $\mathrm{M}_{\mathrm{c}}$, which implies that $\eta_{S}$ and $\eta_{F}$ are not equivalent under any model of $\boldsymbol{\mu}_{1}$ : for example, consider $\left(M_{1}, M_{c}^{m}\right) \in \mu_{1}$. Despite that difficulty, $M_{c}$ probably remains a good choice for the completing model since $M_{c}^{m}$ ensures no more than WME.

\section{Example 4.6: Weak moment efficiency (WME)}

Consider:

$\mathrm{M}_{1}: y_{\mathrm{t}}=\beta x_{\mathrm{t}-1}+\varepsilon_{1 \mathrm{t}}$

$\mathrm{M}_{2}: y_{\mathrm{t}}=\gamma_{\mathrm{t}-1}+\varepsilon_{2 \mathrm{t}}$,

with:

$\mathrm{M}_{\mathrm{c}}^{\mathrm{m}}: x_{\mathrm{t}}=\phi x_{\mathrm{t}-1}+u_{\mathrm{t}}$.

For these $M_{1}$ and $M_{2}$ models, no completing model exists such that SME or SPE is satisfied. $M_{c}^{m}$ ensures WME. The resulting simplification WET statistic $\eta_{S}$ is completely different from the $F$-statistic. For example, the encompassing difference on $\gamma$ has the form:

$$
\tilde{\gamma}-\gamma_{\tilde{\alpha}}=\left(y^{\prime} y\right)^{-1}\left(y^{\prime} Q_{x_{-1}} y_{-1}+y^{\prime} Q_{x_{-1}} x \tilde{\beta}\right)
$$

which tests if $\operatorname{cov}\left(y_{\mathrm{t}}, y_{\mathrm{t}-1} \mid x_{\mathrm{t}-1}\right)+\beta \operatorname{cov}\left(y_{\mathrm{t}}, x_{\mathrm{t}} \mid x_{\mathrm{t}-1}\right)=0$. The $F$-statistic tests if $\operatorname{cov}\left(y_{\mathrm{t}}, y_{\mathrm{t}-1} \mid x_{\mathrm{t}-1}\right)$ is zero. The different possible WET statistics are given in Govaerts [1987] jointly with an 
analysis of their asymptotic power against local alternatives and Monte Carlo simulations to compare their small sample properties. For example, when $M_{1}$ relates $y_{t}$ to $y_{t-2}$ and $M_{2}$ relates $y_{\mathrm{t}}$ to $y_{\mathrm{t}-3}$, the encompassing statistic can be more powerful than the $F$-test.

5.

Conclusion

The general analysis in section 3 and the examples in section 4 reveal that encompassing in linear stationary dynamic processes raises new issues. The need to take account of feedbacks from lagged dependent variables forces the explicit introduction of a completing model, and the choice of its formulation is important if the encompassing tests are to be robust to how the completing model is specified. Six levels of efficiency of the completing model were distinguished, and illustrated by examples that highlighted which features induced which consequences.

The resulting analysis reproduces that previously established for strong exogeneity when the models are static. However, in dynamic systems, a poor choice of the completing model can lead to rejection of the correct hypothesis as shown in the example 4.3.

Stationarity is an important assumption in the approach adopted here because of the central role played by (3.7) and (3.8). In integrated systems with cointegrated relationships, Hendry and Mizon [1993] develop asymptotically valid encompassing tests for linear equations or sub-systems against each other, or the VAR when the latter is the DGP. Similar generalizations should hold for the class of equations of interest above. In particular, parsimonious encompassing is the final check on a reduction sequence, by which stage, mapping to $I(0)$ variables will usually have occurred. However, weak exogeneity only holds in cointegrated systems if the error corrections in the equation of interest do not enter other equations of the system, so that enforces a necessary condition for the present analysis $w$ apply. Further, when weak exogeneity is violated due to the presence of common cointegrating vectors, the limiting distributions are no longer linear mixtures of normals and inference can be distorted (see e.g. Phillips and Loretan [1991] and Hendry, 1993). Nevertheless, both the present analysis and cointegration theory emphasize the primary role of the system in sustaining inference even when interest is in individual equations. 
Overall, our analysis favours the use of parsimonious encompassing tests or $F$-tests as these are more robust to the specification of the completing model, are not restricted to paired comparisons between models and complement general-to-specific modelling strategies. Further, they are invariant to extensions in the specification of the rival model up to the union of all the non-redundant regressors in both models. Finally, when the alternative hypothesis makes the model under test non-congruent, there is a potentially serious power loss in encompassing tests (including non-nested tests) relative to parsimonious encompassing tests. 


\section{Appendix: Minimal Completing Models}

Sample moments are denoted by either $\boldsymbol{A}$ (matrices) or $\boldsymbol{a}$ (scalars and vectors) appropriately subscripted. In particular, let:

$$
\boldsymbol{A}=\frac{1}{T}\left[\begin{array}{ll}
\boldsymbol{X}^{\prime} \boldsymbol{X} & \boldsymbol{X}^{\prime} \boldsymbol{Z} \\
\boldsymbol{Z}^{\prime} \boldsymbol{X} & \boldsymbol{Z}^{\prime} \boldsymbol{Z}
\end{array}\right]=\left[\begin{array}{ll}
A_{\mathrm{XX}} & A_{\mathrm{XZ}} \\
A_{\mathrm{ZX}} & A_{\mathrm{ZZ}}
\end{array}\right]
$$

The ML estimator of $\psi(\alpha)$ is given by $\tilde{\psi}=\boldsymbol{\psi}(\hat{\boldsymbol{\alpha}})$ where $\hat{\alpha}=\left(\hat{\boldsymbol{\beta}}, \hat{\sigma}^{2}, \hat{\Gamma}, \hat{\Sigma}\right)$ regroups the OLS estimators of the parameters in $M_{1}$ and $M_{c}$ as given by (3.1) and (3.4) respectively. Hence EME requires that $A=\psi(\hat{\alpha})$, while SME (WME) requires that $A \approx \psi(\hat{\alpha})$ on $\mathcal{H}\left(\mathcal{M}_{1}\right)$. The following relationships hold:

$$
\begin{array}{ll}
A_{X y}=A_{X X} \hat{\boldsymbol{\beta}} & A_{W R}=\boldsymbol{A}_{W W} \hat{\boldsymbol{\Gamma}} \\
\boldsymbol{A}_{y y}=\hat{\alpha}^{2}+\hat{\boldsymbol{\beta}}^{\prime} \boldsymbol{A}_{X X} \hat{\boldsymbol{\beta}} & \boldsymbol{A}_{R R}=\hat{\Sigma}+\hat{\Gamma}^{\prime} \boldsymbol{A}_{W W} \hat{\boldsymbol{\Gamma}}
\end{array}
$$

Let $\mathrm{L}_{\mathrm{B}}$ denote a list of all the distinct elements in $\left(A_{y y}, A_{X y}, A_{R R}, A_{W R}\right)$. Conditionally on $\boldsymbol{A}_{X X}$ and $\boldsymbol{A}_{W W}$, (A.2) defines a 1-1 mapping between $\mathrm{L}_{B}$ and $\hat{\boldsymbol{\alpha}}$, subject to the usual restrictions for moment matrices (symmetry and positivity). However, in order for $\boldsymbol{A}$ itself to be a function of $\hat{\alpha}$, it has to be the case that $A_{X X}$ and $A_{W W}$, which are included in $A$, can be retrieved from $L_{B}$. For ease of discussion, we restrict attention to the case where all the restrictions between $A, A_{W W}$ and $\mathrm{L}_{\mathrm{B}}$ originate from the exclusion of regressors in $\mathrm{M}_{1}$ and $\mathrm{M}_{\mathrm{c}}{ }^{3}$ Let $\mathrm{L}_{\mathrm{A}}$ denote a list of all the distinct elements in $\boldsymbol{A}$ and $\boldsymbol{A}_{W W}$, then:

$$
\mathrm{L}_{\mathrm{A}} \subseteq \mathrm{L}_{\mathrm{B}}
$$

is - for all practical purposes - necessary and sufficient for $A$ to be a function of $\hat{\alpha}$. A formal proof of that assertion requires explicitly stating a number of technical conditions and goes beyond the objectives of the current paper. At a more heuristic level, if condition (A.3) holds, then (A.2) can be solved (recursively) for $\boldsymbol{A}$ : at step $j$ of the recursion, $\boldsymbol{A}_{X X}$ and $\boldsymbol{A}_{W W}$ are set at the values obtained on step (j-1) and (A.2) is solved for $\mathrm{L}_{B} ; \boldsymbol{A}_{X X}$ and $\boldsymbol{A}_{W W}$ are then updated and the procedure is repeated until convergence (which follows from a fixed point theorem). If, on the other hand, $A$ is a function of $\hat{\alpha}$, then (A.3) holds. If, indeed, an element of $\mathrm{L}_{\mathrm{A}}$ were not included in $\mathrm{L}_{\mathrm{B}}$, then we could assign an arbitrary value to that element and proceed as just described. That element would never be revised, contradicting

\footnotetext{
3 Accounting for more general linear restrictions among the variables in MY raises no conceptual problems but necessitates additional algebraic manipulations of the relevant moment matrices.
} 
the assertion that $\boldsymbol{A}$ is a function of $\hat{\boldsymbol{\alpha}}$ alone.

The algorithm we propose aims to select a (minimal) set of regressors for $w_{t}$ in such a way that condition (A.3) holds. Two additional issues deserve attention before we can describe the algorithm:

(1) The only difference between EME and SME lies in the treatment of initial and terminal observations in the sample. For example, under EME, moments such as $T^{-1} \boldsymbol{x}^{\prime} \boldsymbol{y}_{-1}$ and $T^{-1} x_{-1}^{\prime} \boldsymbol{y}_{-2}$ are treated as different entities while, under SME, they are conflated with each other. Our proposed algorithm trivially accommodates that distinction;

(2) $\boldsymbol{w}_{\mathrm{t}}$ consists of lagged variables only, while $\boldsymbol{r}_{\mathrm{t}}$ regroups all current exogenous variables. It follows that $\boldsymbol{A}_{R W}$ cannot include cross-moments between $x \mathrm{~s}$ and leading $y \mathrm{~s}$. If any such moments are included in $\mathrm{L}_{\mathrm{A}}$, then $\mathrm{EME}$ (SME) cannot be obtained. Let $\overline{\boldsymbol{x}}_{\mathrm{t}}$ consist of all regressors that are excluded from $M_{1}$. The following asymptotic equivalence holds on $M_{1}$ :

$$
\boldsymbol{A}_{\overline{\boldsymbol{x}} y} \underset{\mathscr{H}_{1}}{\approx} A_{X X} A_{X X}^{-1} a_{x y}
$$

Both $\boldsymbol{A}_{X X}$ and $a_{x y}$ are already covered by an analysis of condition (A.3). Hence, for the purpose of achieving WME, we can replace components of $\boldsymbol{A}_{\bar{x} y}$ in $\mathrm{L}_{\mathrm{A}}$ by the corresponding elements of $\boldsymbol{A}_{X X}$ and proceed.

The proposed algorithm follows from the above discussion. We initially set $w_{\mathrm{t}}=\emptyset$ and accordingly define $\mathrm{L}_{A}$ and $\mathrm{L}_{B}$. We then examine whether condition (A.3) holds. Each time an element of $\mathrm{L}_{A}$ is found to be missing in $\mathrm{L}_{B}, \boldsymbol{w}_{\mathrm{t}}$ is 'augmented' according to one of the following two (mutually exclusive) schemes:

Type-A augmentation: direct augmentation of $w_{\mathrm{t}}$ such that the missing element is included in the augmented $\mathrm{L}_{\mathrm{B}}$;

Type-B augmentation: the missing element belongs to $\boldsymbol{a}_{\overline{\boldsymbol{x}} \boldsymbol{y}}$; it is replaced by the corresponding elements in $\boldsymbol{A}_{\mathrm{XX}}$, and $\boldsymbol{w}_{\mathrm{t}}$ is then augmented in such a way that the latter are included in the augmented $L_{B}$.

The algorithm is finite and generates a 'minimal' completing model under which WME holds. Further, if it necessitates only type-A augmentations, then EME (SME) obtains. All the minimal completing models $M_{c}^{m}$, to which we refer in section 4 , have been obtained by application of this algorithm. 


\section{REFERENCES}

Cox, David R., 1961, Tests of Separate Families of Hypotheses, Proceedings of the Fourth Berkeley Symposium on Mathematical Statistics and Probability, Vol. I, 105-123, University of California Press, Berkeley.

Cox, David R., 1962, Further Results on Tests of Separate Families of Hypotheses, Journal of the Royal Statistical Society, B, 24, 406-424.

Engle, Robert F., Hendry, David F. and Richard, Jean-François, 1983, Exogeneity, Econometrica, 51, 277-304.

Florens, Jean-Piérre, Hendry, David F. and Richard, Jean-François, 1988, Parsimonious Encompassing: An Application to Non-Nested Hypotheses and Hausman Specification Tests, ISDS discussion paper, Duke University, N.C., USA.

Florens, Jean-Piérre, Hendry, David F. and Richard, Jean-François, 1991, Encompassing and Specificity, Cahier 91c, GREMAQ, University of Toulouse.

Gourieroux, Christian, Monfort, Alain and Trognon, Alain, 1984, Pseudo-Maximum Likelihood Methods: Theory, Econometrica, 52, 681-700.

Gourieroux, Christian and Monfort, Alain, 1991, Testing Non-nested Hypotheses, mimes. INSEE.

Gourieroux, Christian and Monfort, Alain, 1992, Testing, Encompassing and Simulating Dynamic Econometric Models, mimeo, INSEE.

Govaerts, Bernadette, 1987, Application of the Encompassing Principle to Linear Dynamic Models, Ph.D. Dissertation, Universite Catholique de Louvain, Belgium.

Govaerts, Bernadette, 1988, A Note on a Method to Compute the Asymptotic Distribution of the Sample Second-Order Moments of Dynamic Linear Normal Variables, Communications in Statistics.

Granger, Clive W.J., 1969, Investigating Causal Relations by Econometric Models and Cross-Spectral Methods, Econometrica, 37, 424-438.

Hannan, Edward G., 1970, Multiple Time Series, John Wiley: New York.

Hendry, David F., 1993, Lectures on Econometric Methodology. Forthcoming, Oxfotd University Press.

Hendry, David F. and Mizon, Grayham E., 1993, Evaluating Dynamic Econometric Models by Encompassing the VAR, p272-300 in Peter C.B. Phillips (ed.), Models, Methods and Applications of Econometrics. Oxford: Basil Blackwell.

Hendry, David F., Neale, Adrian J. and Ericsson, Neil R., 1991, PC-NAIVE: An Interactive Program for Monte Carlo Experimentation in Econometrics. Oxford: Oxford Institute of Economics and Statistics.

Hendry, David F. and Richard, Jean-François, 1982, On the Formulation of Empirical Models in Dynamic Econometrics, Journal of Econometrics, 20, 3-33.

Hendry, David F. and Richard, Jean-François, 1983, The Econometric Analysis of Economic Time Series, International Statistical Review, 51, 111-163.

Hendry, David F. and Richard, Jean-François, 1990, Recent Developments in the Theory of Encompassing, p393-440 in Bernard Cornet and Henry Tulkens (eds.), Contributions to Operations Research and Econometrics. The XXth Anniversary of CORE, Cambridge, Mass.: M.I.T. Press.

Kent, John T. (1986), "The Underlying Nature of Nonnested Hypothesis Tests", Biometrika, 73, 333-43.

Mann, H.B. and Wald, Abraham, 1943, On the Statistical Treatment of Linear Stochastic Difference Equations, Econometrica, 11, 173-220. 
Mizon, Grayham E., 1984, The Encompassing Approach in Econometrics, p135-72 in D.F. Hendry and K.F. Wallis (eds.), Econometrics and Quantitative Economics, Oxford: Basil Blackwell.

Mizon, Grayham E. and Hendry, David F., 1980, An Empirical Application and Monte Carlo Analysis of Tests of Dynamic Specification, Review of Economic Studies, 47, 2146.

Mizon, Grayham E. and Richard, Jean-François, 1986, The Encompassing Principle and its Application to Non-Nested Hypotheses, Econometrica, 54, 657-78.

Pesaran, Hashem M., 1987, Global and Partial Non-nested Hypotheses and Asymptotic Local Power, Econometric Theory, 3, 69-90.

Phillips, Peter C.B. and Loretan, Mico, 1991, Estimating Long-run Economic Equilibria, Review of Economic Studies, 53, 473-95.

Sawa, Takeshi, 1978, Information Criteria for Discriminating Among Alternative Regression Models, Econometrica, 46, 1273-92.

White, Halbert (ed.), 1983, Non-nested Models, Special Issue of Journal of Econometrics, 21.

White, Halbert, 1984, Asymptotic Theory for Econometricians, New York: Academic Press Inc. 


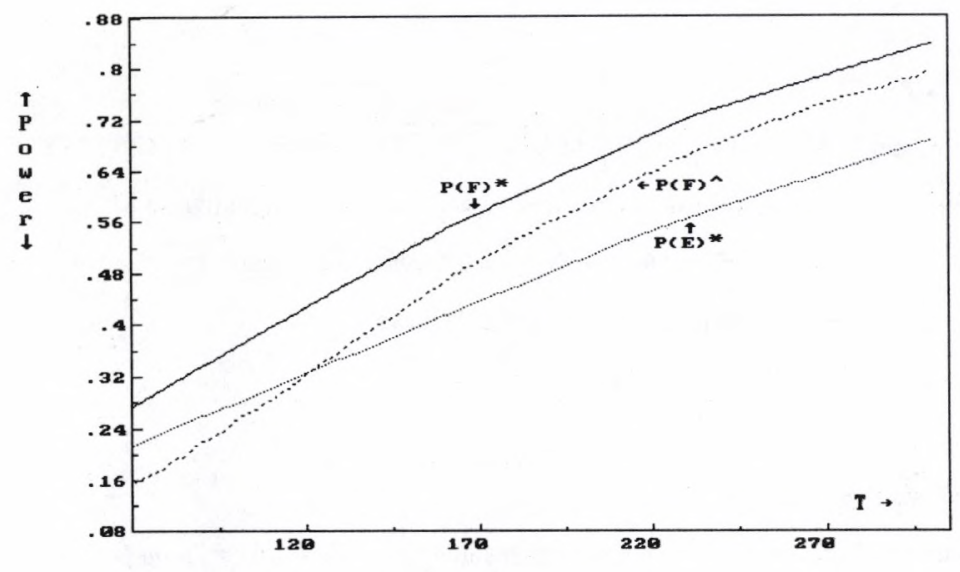

Figure 1

Asymptotic and finite sample power functions of the $F$-test and the encompassing test: $\mathrm{P}(F)^{*}$ and $\mathrm{P}(E)^{*}$ are asymptotic, $\mathrm{P}(F)^{\wedge}$ is based on recursive Monte Carlo: example 4.2 


\section{Appendix A: Asymptotic Power Functions of $\eta_{F}$ and $\eta_{C}$.}

The rival models are:

$\mathrm{M}_{1}: \quad y_{\mathrm{t}}=\beta y_{\mathrm{t}-2}+\varepsilon_{1 \mathrm{t}}$

$\mathrm{M}_{2}: y_{\mathrm{t}}=\gamma \gamma_{\mathrm{t}-1}+\varepsilon_{2 \mathrm{t}}$

The completing model is $\mathrm{M}_{2}$. The $\eta_{F}$ and $\eta_{C}$ tests are given by equations (4.11) and (4.9) with $\eta_{C} \leq \eta_{F}$, but they are asymptotically equivalent on $M_{1}$. The local alternative to $M_{1}$ is: (A1) $\quad y_{\mathrm{t}}=T^{\frac{1}{2}} v_{1} y_{\mathrm{t}-1}+v_{2} y_{\mathrm{t}-2}+\zeta_{\mathrm{t}}=\theta y_{\mathrm{t}-1}+v_{2} y_{\mathrm{t}-2}+\zeta_{\mathrm{t}}$ where $\zeta_{\mathrm{t}} \sim \mathrm{IN}\left(0, \sigma_{\zeta}^{2}\right)$.

The plims of the data second moments under (A1) are as follows:

(A2) $\quad \sum_{\mathrm{yy}}=\left(1-v_{2}\right) \sigma_{\zeta}^{2} /\left[\left(1+v_{2}\right)\left\{\left(1-v_{2}\right)^{2}-\theta^{2}\right\}\right]$;

(A3) $\quad \sum_{y_{-1}}=\theta \sum_{y y} /\left(1-v_{2}\right)$;

(A4) $\quad \Sigma_{\mathrm{yy}_{-2}}=\left[v_{2}\left(1-v_{2}\right)+\theta^{2}\right] \Sigma_{\mathrm{yy}} J\left(1-v_{2}\right)$.

Thus, estimation of $M_{1}$ leads to population parameter values $\beta_{p}=p \lim \tilde{\beta}$, and $\sigma_{\mathrm{p}}^{2}=\operatorname{plim} \tilde{\sigma}^{2}$ :

(A5) $\quad \beta_{\mathrm{p}}=\Sigma_{\mathrm{yy}}^{-1} \Sigma_{\mathrm{yy}}=\left[v_{2}\left(1-v_{2}\right)+\theta^{2}\right] /\left(1-v_{2}\right)$,

and:

(A6) $\quad \sigma_{\mathrm{p}}^{2}=\sigma_{\zeta}^{2}\left(1+\left[\left(1-v_{2}\right) \theta^{2} /\left(1+v_{2}\right)\left\{\left(1-v_{2}\right)^{2}-\theta^{2}\right\}\right]\right)$.

On local alternatives like (A1), the $\eta_{\bullet}$ tests become non-central $\chi^{2}\left(1, \mu^{2}\right)$ where (see Mizon and Hendry, 1980):

$$
\begin{aligned}
\mu^{2}\left(\eta_{F}\right) & =v_{1}^{2} /\left(1-v_{2}^{2}\right)=\mathrm{T} \theta^{2} /\left(1-v_{2}^{2}\right) \\
\mu^{2}\left(\eta_{C}\right) & =\sigma_{\zeta}^{2} v_{1}^{2}\left\{\left(1-v_{2}\right)^{2}-\theta^{2}\right\} / \sigma_{\mathrm{p}}^{2}\left(1-v_{2}^{2}\right)\left(1-v_{2}\right)^{2} \\
& =\mu^{2}\left(\eta_{F}\right)\left[1-2 \theta^{2} /\left(1-v_{2}^{2}\right)\left(1-v_{2}\right)\right]+o_{\mathrm{p}}\left(\mathrm{T}^{-1}\right) \\
& \leq \mu^{2}\left(\eta_{F}\right) .
\end{aligned}
$$

Two factors contribute to the power loss arising from the uniformly smaller noncentrality parameter: on (A1), $\sigma_{\mathrm{p}}^{2} \geq \sigma_{\zeta}^{2}$, which $\eta_{F}$ avoids; and $\beta_{\mathrm{p}} \neq \beta$, so the residuals are not white noise, whereas $\zeta_{\mathrm{t}}$ is. Even though $\theta$ is $\mathrm{O}\left(\mathrm{T}^{-\frac{1}{2}}\right)$, the asymptotic power loss is quite large as figure 1 shows when $\theta=0.1$, and $v_{2}=0.8$ for $\mathrm{T}=10, \ldots, 300$. 


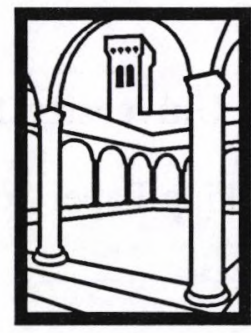

EUI

WORKING

PAPERS

EUI Working Papers are published and distributed by the European University Institute, Florence

Copies can be obtained free of charge

- depending on the availability of stocks - from:

The Publications Officer

European University Institute

Badia Fiesolana

I-50016 San Domenico di Fiesole (FI)

Italy 


\section{圖 \\ Publications of the European University Institute \\ Economics Department Working Paper Series}

To

Department of Economics WP

European University Institute

Badia Fiesolana

I-50016 San Domenico di Fiesole (FI)

Italy

From Name

Address.

(Please print)

$\square$ Please enter/confirm my name on EUI Economics Dept. Mailing List

$\square$ Please send me a complete list of EUI Working Papers

$\square$ Please send me a complete list of EUI book publications

$\square$ Please send me the EUI brochure Academic Year 1994/95

Please send me the following EUI ECO Working Paper(s):

No, Author

Title:

No, Author

Title:

No, Author

Title:

No, Author

Title:

Date

Signature 


\section{Working Papers of the Department of Economics Published since 1993}

\section{ECO No. 93/1}

Carlo GRILLENZONI

Forecasting Unstable and Non-Stationary Time Series

ECO No. 93/2

Carlo GRILLENZONI

Multilinear Models for Nonlinear Time Series

ECO No. 93/3

Ronald M. HARSTAD/Louis PHLIPS Futures Market Contracting When You Don't Know Who the Optimists Are

ECO No. 93/4

Alan KIRMAN/Louis PHLIPS

Empirical Studies of Product Markets

ECO No. 93/5

Grayham E. MIZON

Empirical Analysis of Time Series: Illustrations with Simulated Data

ECO No. 93/6

Tilman EHRBECK

Optimally Combining Individual

Forecasts From Panel Data

ECO NO. 93/7

Víctor GÓMEZ/Agustín MARAVALL Initializing the Kalman Filter with Incompletely Specified Initial Conditions

ECO No. 93/8

Frederic PALOMINO

Informed Speculation: Small Markets

Against Large Markets

ECO NO. 93/9

Stephen MARTIN

Beyond Prices Versus Quantities

ECO No. 93/10

José María LABEAGA/Angel LÓPEZ A Flexible Demand System and VAT Simulations from Spanish Microdata

ECO No. 93/11

Maozu LU/Grayham E. MIZON The Encompassing Principle and Specification Tests
ECO No. 93/12

Louis PHLIPS/Peter MØLLGAARD

Oil Stocks as a Squeeze Preventing

Mechanism: Is Self-Regulation Possible?

ECO No. 93/13

Pieter HASEKAMP

Disinflation Policy and Credibility: The

Role of Conventions

ECO No. 93/14

Louis PHLIPS

Price Leadership and Conscious

Parallelism: A Survey

ECO No. 93/15

Agustín MARAVALL

Short-Term Analysis of Macroeconomic Time Series

ECO No. 93/16

Philip Hans FRANSES/Niels

HALDRUP

The Effects of Additive Outliers on Tests for Unit Roots and Cointegration

ECO No. 93/17

Fabio CANOVA/Jane MARRINAN

Predicting Excess Returns in Financial Markets

ECO No. 93/18

Iñigo HERGUERA

Exchange Rate Fluctuations, Market

Structure and the Pass-through

Relationship

ECO No. 93/19

Agustín MARAVALL

Use and Misuse of Unobserved

Components in Economic Forecasting

ECO No. 93/20

Torben HOLVAD/Jens Leth

HOUGAARD

Measuring Technical Input Efficiency for Similar Production Units:

A Survey of the Non-Parametric Approach 
ECO No. 93/21

Stephen MARTIN/Louis PHLIPS

Product Differentiation, Market Structure

and Exchange Rate Passthrough

ECO No 93/22

F. CANOVA/M. FINN/A. R. PAGAN

Evaluating a Real Business Cycle Model

ECO No 93/23

Fabio CANOVA

Statistical Inference in Calibrated Models

ECO No 93/24

Gilles TEYSSIËRE

Matching Processes in the Labour Market in Marseilles. An Econometric Study

\section{ECO No 93/25}

Fabio CANOVA

Sources and Propagation of International

Business Cycles: Common Shocks or

Transmission?

ECO No. 93/26

Marco BECHT/Carlos RAMÍREZ

Financial Capitalism in Pre-World War I

Germany: The Role of the Universal

Banks in the Financing of German

Mining Companies 1906-1912

ECO No. 93/27

Isabelle MARET

Two Parametric Models of Demand,

Structure of Market Demand from

Heterogeneity

ECO No. 93/28

Stephen MARTIN

Vertical Product Differentiation, Intra-

industry Trade, and Infant Industry

Protection

ECO No. 93/29

J. Humberto LOPEZ

Testing for Unit Roots with the k-th

Autocorrelation Coefficient

ECO No. 93/30

Paola VALBONESI

Modelling Interactions Between State and

Private Sector in a "Previously" Centrally

Planned Economy
ECO No. 93/31

Enrique ALBEROLA ILA/J. Humberto LOPEZ/Vicente ORTS RIOS

An Application of the Kalman Filter to the Spanish Experience in a Target Zone (1989-92)

ECO No. 93/32

Fabio CANOVA/Morten O. RAVN

International Consumption Risk Sharing

ECO No. 93/33

Morten Overgaard RAVN

International Business Cycles: How much can Standard Theory Account for?

ECO No. 93/34

Agustín MARAVALL

Unobserved Components in Economic

Time Series

ECO No. 93/35

Sheila MARNIE/John

MICKLEWRIGHT

"Poverty in Pre-Reform Uzbekistan:

What do Official Data Really Reveal?"

ECO No. 93/36

Torben HOLVAD/Jens Leth

HOUGAARD

Measuring Technical Input Efficiency for

Similar Production Units:

80 Danish Hospitals

ECO No. 93/37

Grayham E. MIZON

A Simple Message for Autocorrelation

Correctors: DON'T

ECO No. 93/38

Barbara BOEHNLEIN

The Impact of Product Differentiation on Collusive Equilibria and Multimarket

Contact

ECO No. 93/39

H. Peter MØLLGAARD

Bargaining and Efficiency in a

Speculative Forward Market

粠米 
ECO No. 94/1

Robert WALDMANN

Cooperatives With Privately Optimal

Price Indexed Debt Increase Membership

When Demand Increases

ECO No. 94/2

Tilman EHRBECK/Robert

WALDMANN

Can Forecasters' Motives Explain

Rejection of the Rational Expectations

Hypothesis?

ECO No. 94/3

Alessandra PELLONI

Public Policy in a Two Sector Model of

Endogenous Growth

ECO No. 94/4

David F. HENDRY

On the Interactions of Unit Roots and

Exogeneity

ECO No. 94/5

Bernadette GOVAERTS/David F.

HENDRY/Jean-François RICHARD

Encompassing in Stationary Linear

Dynamic Models 


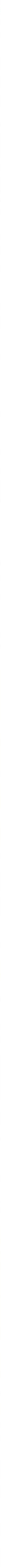

